IZA DP No. 10013

Pension Incentives and the Retirement Decisions of Couples

Kadir Atalay

Garry F. Barrett

June 2016 


\title{
Pension Incentives and the Retirement Decisions of Couples
}

\author{
Kadir Atalay \\ University of Sydney \\ Garry F. Barrett \\ University of Sydney \\ and IZA
}

Discussion Paper No. 10013

June 2016

IZA

P.O. Box 7240

53072 Bonn

Germany

Phone: +49-228-3894-0

Fax: +49-228-3894-180

E-mail: iza@iza.org

Any opinions expressed here are those of the author(s) and not those of IZA. Research published in this series may include views on policy, but the institute itself takes no institutional policy positions. The IZA research network is committed to the IZA Guiding Principles of Research Integrity.

The Institute for the Study of Labor (IZA) in Bonn is a local and virtual international research center and a place of communication between science, politics and business. IZA is an independent nonprofit organization supported by Deutsche Post Foundation. The center is associated with the University of Bonn and offers a stimulating research environment through its international network, workshops and conferences, data service, project support, research visits and doctoral program. IZA engages in (i) original and internationally competitive research in all fields of labor economics, (ii) development of policy concepts, and (iii) dissemination of research results and concepts to the interested public.

IZA Discussion Papers often represent preliminary work and are circulated to encourage discussion. Citation of such a paper should account for its provisional character. A revised version may be available directly from the author. 
IZA Discussion Paper No. 10013

June 2016

\begin{abstract}

\section{Pension Incentives and the Retirement Decisions of Couples}

Recent reforms to social security in many countries have sought to delay retirement. Given the family context in which retirement decisions are made, social security reforms have potentially important spill-over effects on the participation of spouses. This paper analyses the impact of women's pension incentives on the retirement decision of their husband. The 1993 Age Pension reform in Australia increased the eligibility age for Age Pension benefits for women. This reform caused an increase in participation of men married to women in the affected cohorts. The behavioral responses are due to wealth effects and preferences for shared leisure.
\end{abstract}

JEL Classification: D91, I38, J26

Keywords: retirement, age pension, joint retirement, spousal effect

Corresponding author:

Garry F. Barrett

School of Economics

University of Sydney

2006 Australia

Australia

E-mail: garry.barrett@sydney.edu.au

${ }^{*}$ Funding from the Australian Research Council is gratefully acknowledged. 


\section{INTRODUCTION}

Recent pension reforms in many countries have aimed to increase the labour force participation of elderly individuals (OECD 2011). Most research (Gruber and Wise 2004; Mastrobuoni 2009; Staubli and Zweimuller 2013; Hanel and Riphahn 2012; Atalay and Barrett 2015; Danzer 2013; Vestad 2013) evaluating the reforms has focused on the individuals directly targeted by the program changes, neglecting potential "spill-over effects" on spouses of those affected. Although models of joint retirement decision making (Coile 2004; Casanova 2010) emphasize the importance of within family spill-over effects, empirical evidence on the magnitude of the causal effects is very limited. In this paper we provide an empirical assessment of the causal effect of increasing the social security benefit eligibility age for women on the labour supply decisions of their husbands.

A relatively new body of literature examines interactions between spouses and discusses the problems associated with identifying causal effects in reduced form studies ${ }^{1}$ (Hurd 1990, Zweimuller et al. 1996, Blau 1998, Baker 2002, Coile 2004, Banks et al. 2010 and Selin 2012). The critical challenge is identification; ensuring that the estimated spill-over effects represent behavioural responses to retirement incentives rather than a reflection of taste heterogeneity which may arise, for example, through assortative marriages between individuals with similar unobserved preferences over leisure and consumption. Given this complication, one strategy pursued by Baker (2002) and then Selin (2012), Stancanelli (2012) and Cribb, Emmerson and Tetlow (2013) involves the use of a difference-in-differences approach using social security reforms. The advantage of this approach is that program reforms can provide credible exogenous variation in benefits within similar families. If a suitable control group is available it is possible to control for general time effects under a 'common trends' assumption which helps to isolate pure spill-over effects. Baker (2002) studies the 1975 introduction of the Spouses' Allowance to the Canadian Income Security System, which provided a strong incentive for eligible women and their husband to withdraw from the labour force earlier because of the means testing of benefits. Baker finds significant spill-over effects for men. Banks, Blundell and Casanova (2010) use the difference in the age of entitlement of women

\footnotetext{
${ }^{1}$ An alternative approach to reduced form studies is estimating structural models of family retirement: see, for example, Gustman and Steinmeier 2004, Casanova 2010.
} 
to public pensions in the US and UK to examine men' response to their wife's retirement incentives. $^{2}$ Their results indicate a significant spillover effects on participation ranging from to 14 to 20 percent. Recently, a series of papers have examined how reforms to early and normal retirement ages directly influencing the retirement decision of one spouse also impact the retirement decision of their partner. Selin (2012) exploits pension reform in Sweden, which introduced a defined contribution system and provides incentives for elderly female public employees to remain in the labour force. His results show no spill-over effect. Stancanelli (2012) studies early retirement age legislation in France and finds an increase in the retirement probability, and a fall in work hours, of a husband upon his wife reaching early retirement age. Cribb et al. (2013) studies the recent UK reform which increases the state retirement age for women. They find an increase in the employment rates of husbands married to women affected by the reform. We contribute new evidence using a recent, unique Australian policy experiment that provided strong incentives for women to remain in the labour force longer.

More specifically, we study the 1993 Age Pension (AP) reform in Australia which increased the eligibility age to access public pension payments for women. The increase to the Age Pension eligibility age (hereafter APA) represents a reduction in the social security wealth of the affected cohorts of women, and their families, and provides an ideal natural experiment to study the incentives of the AP program. We investigate the extent to which this policy reform had an unintended side effect of inducing a change in the labour force participation of married men.

This analysis is an important contribution to retirement policy based on the unique features of the recent and substantial reform to the Australian pension program. First, the Australian AP program is a non-contributory scheme; eligibility does not require prior employment nor are benefit levels conditional on prior earnings. Therefore the reform also has an effect on families in which women have no work history. This is in contrast to the French, Swedish and UK reforms examined in previous studies where changes in normal or early retirement ages only affected the subpopulation with work histories. Second, AP ben-

\footnotetext{
${ }^{2}$ The empirical strategy is a difference-in-difference approach where the control group is drawn from an otherwise similar country with a different entitlement age, rather individuals in the same country who were unaffected by a pension reform.
} 
efits in Australia are independent of prior earnings and there is no accrual of higher benefits with delayed retirement. Consequently the accrual effect of continued employment on social security wealth is absent. The lack of accrual effects from delayed retirement renders the Australian experiment especially clean for studying the spillover effects through exogenous changes in social security wealth, as comparable reforms in other industrial economies need to carefully model strong accrual effects. Third, due to the nature of the reform we have several treatment groups with differing strengths of treatment, providing a quasi-experimental setting in which we can investigate the labour force decisions of husbands whose wives are subject to differing treatment intensity. Fourth, the Australian experiment offers valuable insights to the effects of a reform that is currently being implemented in many countries, especially in Europe.

Our results indicate that an increase in the pension eligibility age of women is associated with an increase in the labour force participation of married women, and leads to an increase in the labour force participation of men who are married to women in the affected cohorts. These behavioral responses are explained by a combination of life-cycle wealth effects and complementarities in spouses' tastes for leisure.

In the next section, we describe the AP reforms and discuss the implications on the partners of affected women. In section 3, we introduce our data and empirical strategy. Section 4 presents the results, and the final section concludes the paper.

\section{AUSTRALIAN AGE PENSION REFORM}

The Australian retirement income system ${ }^{3}$ consists of a means-tested public AP plus mandatory and voluntary private savings. In Australia, there is no compulsory retirement age, and elderly Australians can supplement their retirement income through continued employment. The AP was introduced in 1909 and although it has undergone a number of changes, the program has always remained the fundamental safety net for older Australians. In June 2010, approximately 70\% of elderly couples received some benefit from the AP program, which constituted the main source of income for the majority of beneficiaries.

The maximum benefit payment from the Age Pension is set at $25 \%$ of male total av-

\footnotetext{
${ }^{3}$ For detailed information on the Australian pension system see Barrett and Tseng (2008).
} 
erage earnings. Recipients may receive subsidies for health care, pharmaceuticals, public transport, utilities and private rental assistance plus a supplement to compensate for the introduction of the national good and service tax in 2000. As at July 1, 2010, at the end of our observation period, the maximum Age Pension benefit was AUD $\$ 971.20$ per fortnight per couple (combined) or AUD $\$ 644.20$ for singles. This maximum benefit is subject to an income and assets test. The income test is based on a threshold ("income disregard") of $\$ 256$ (\$146) per fortnight for couples (singles), above which benefits are reduced by 50 cents (25 cents) for each dollar of income. The asset test depends on the home ownership status of the applicant. For homeowners, the threshold ("asset disregard") is $\$ 258,000(\$ 181,750)$ for couples (singles), and for non-homeowners the asset disregard is $\$ 389,500(\$ 313,250)$ for couples (singles). Pension benefits are reduced by $\$ 1.50$ per fortnight for every $\$ 1,000$ in excess of the asset disregard. ${ }^{4}$ The income or asset test which results in lower benefits is the one which is determine the level of benefits paid. In 2010, two-thirds of all Age Pension recipients received the maximum pension payment. ${ }^{5}$

Eligibility for the AP is subject to residency and age conditions. Individuals need to have resided in Australia for 10 years prior to application. There are different age requirements for male and female applicants. Since its inception the AP qualifying age (APA) for men has remained at 65 years. However, the qualifying age for female applicants has undergone a gradual increase since 1995, from the initial 60 years of age (for females born on or before 30 June 1935), the APA has gradually increased by six months for each subsequent 18month birth cohort. The eligibility age eventually reaches 65 years for women born after 1st January 1949. The eligibility ages for women belonging to different cohorts are illustrated in Figure 1. Females born before 1 July 1935 can first collect the AP at age 60 years, whereas females born between January 1940 and 30 June 1941 become eligible for the AP at age 62 years. As a result of APA reform, two couples with the same age distribution, for example the husband is 63 and the wife is 61 years old, but where the women belong to different birth cohorts will face different APAs. ${ }^{6}$ In the empirical analysis we exploit this exogenous

\footnotetext{
${ }^{4}$ Benefit levels, and the means test thresholds, are adjusted every six months in line with changes in the consumer price index or average (ordinary time) male earnings - whichever is greater.

${ }^{5}$ As the means test was relaxed over time, the participation rate increased, peaking at over $85 \%$ in the 1980's when the assets test was suspended. The Age Pension more closely resembles a general entitlement rather than a tightly targeted benefit.

${ }^{6}$ Note that a couple can receive AP benefits once one spouse reaches APA, subject to meeting the means
} 
variation in eligibility age to analyse the spill-over in spousal retirement choices.

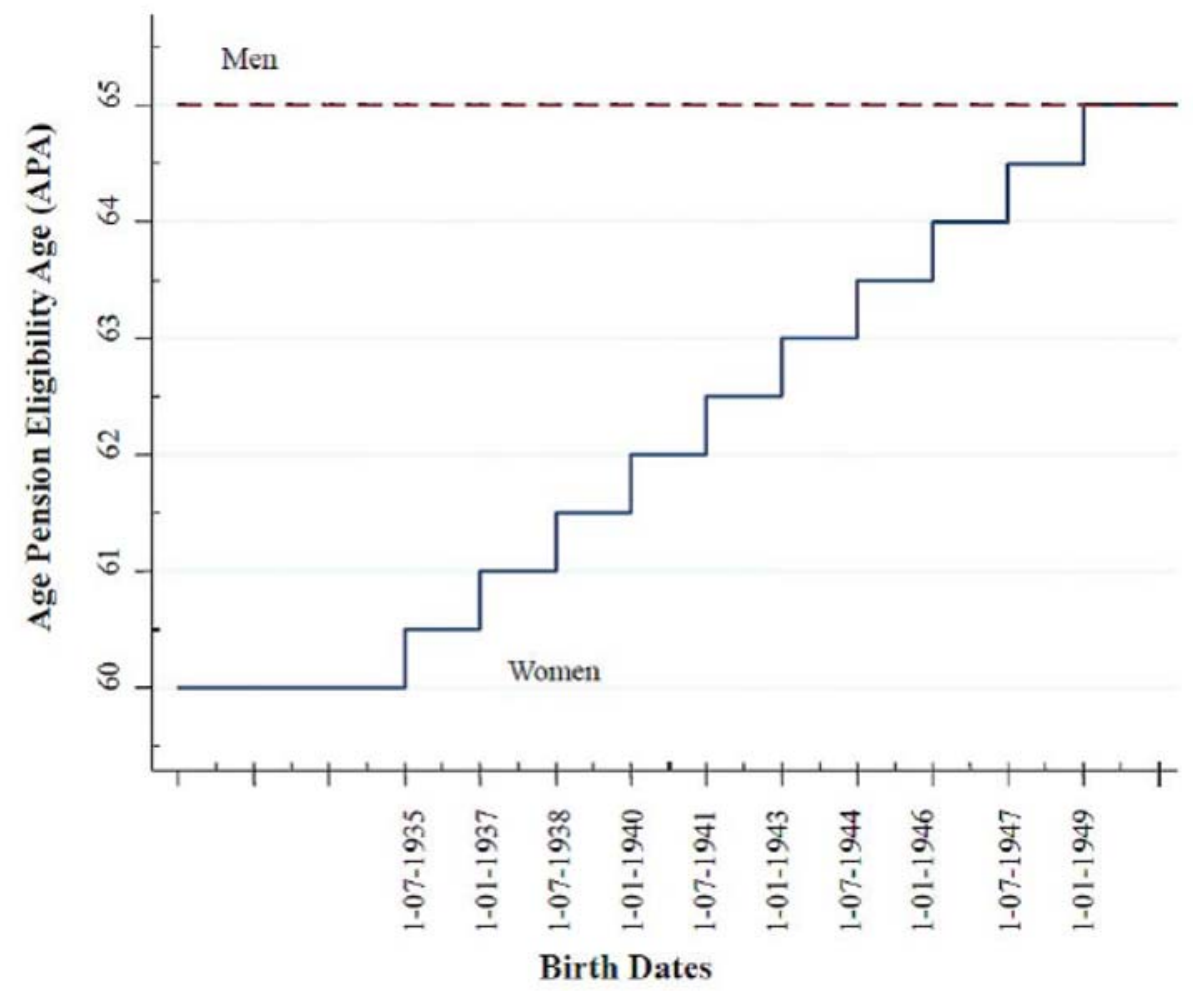

\section{Figure 1.}

Australian Age Pension Eligibility Age

This reform of the Australian social security system represents an unambiguous decline in the social security wealth of women and their families. Each six-month delay in the receipt of AP benefits corresponds to an approximate 2.5 percent reduction in the discounted present value of their expected social security wealth; a five year delay corresponds to an approximate 23 percent reduction in expected social security wealth. This APA reform represents a substantial exogenous change in social security wealth. Atalay and Barrett (2015) study this reform and find an increase in work propensity among women in the affected cohorts. However their account of spousal behaviour is limited as they focus on single women (and men) in order to eliminate potential within-family spill-over effects in test. If both adults are age eligible, they receive the couple benefit conditional on the couple-specific means test. If only one adult in a couple is age eligible, they receive the singles benefit subject to the means test which takes account of family earnings. 
their difference-in-difference identification strategy. In this paper the focus is on directly gauging the magnitude of the response of married men's retirement choice to the changed retirement incentives induced by the APA reform targeting their spouse.

Changes to women's APA may influence the labour force participation decisions of husbands through several channels. To lay out the potential mechanisms involved we present a life-cycle model of joint retirement. The purpose of the model is to illustrate the wealth and shared leisure effects arising from the change in women's APA.

Consider a model of a joint retirement such as that developed in Gustman and Steinmeier $(2000,2004)$. At a point in time, utility of the husband $U^{h}\left(C_{t}, L_{t}^{h}, L_{t}^{w}\right)$ is defined over family consumption $C_{t}$ and own leisure time $L_{t}^{h}$. Wife's leisure time $L_{t}^{w}$ enters the husband's utility function as a preference shifter such that husbands value leisure more when his wife is also not working $\left(\frac{\partial^{2} U^{h}}{\partial L_{t}^{h} \partial L_{t}^{w}}>0\right)$. Assume each spouse has a known, finite lifetime of $T$ years, $R$ is the age of retirement, and retirement is an absorbing state. For simplicity assume leisure is a discrete decision, normalized to 0 for working life and 1 for retirement; leisure then varies only by the retirement decision $R$. The husband's lifetime utility is given by

$$
V^{h}=\int_{0}^{R^{h}} U^{h}\left(C_{t}, 0, L_{t}^{w}\right) e^{-\delta t} d t+\int_{R^{h}}^{T} U^{h}\left(C_{t}, 1, L_{t}^{w}\right) e^{-\delta t} d t
$$

and the wife's lifetime utility is defined symmetrically as

$$
V^{w}=\int_{0}^{R^{w}} U^{w}\left(C_{t}, L_{t}^{h}, 0\right) e^{-\delta t} d t+\int_{R^{w}}^{T} U^{w}\left(C_{t}, L_{t}^{h}, 1\right) e^{-\delta t} d t
$$

Each spouse seeks to maximize their respective lifetime utility subject to the life-time family budget constraint:

$$
\int_{o}^{T} C_{t} e^{-r t} d t=\int_{o}^{R^{h}} Y_{t}^{h} e^{-r t} d t+\int_{o}^{R^{w}} Y_{t}^{w} e^{-r t} d t+\int_{0}^{T} S S W_{t}\left(t_{q}^{h}, t_{q}^{w}, Y_{t}^{h}+Y_{t}^{w}\right) e^{-r t} d t
$$

The budget constraint in (1) shows that the total value of discounted family consumption at interest rate $r$ must equal to the discounted value of of income from three sources; the discounted value of both spouses' labour income earned over their working life $Y_{t}^{j}=\left(1-L_{h}^{j}\right) w_{t}^{j}$ where $w_{t}^{j}$ is the wage of spouse $j$, plus family AP wealth $S S W=\int_{0}^{T} S S W_{t}\left(t_{q}^{h}, t_{q}^{w}, Y_{t}^{h}+Y_{t}^{w}\right)$ $e^{-r t} d t$. Family social security wealth is conditional on ages $\left(t_{q}^{h}, t_{q}^{w}\right)$ at which the husband and wife qualify for AP benefits, and on family earned income in each period due to the means test. Features of the Australian AP program, such as the lack of accurial of future 
benefits from delayed claiming, result in an increase in women's APA being equivalent to a decline in social security wealth: $\partial S S W_{t} / \partial t_{q}^{w} \leq 0$.

To solve for the optimal path of family consumption $\left\{C_{t}\right\}_{t=0}^{T}$ and retirement dates $\left(R^{h}, R^{w}\right)$, Gustman and Steinmeier (2000) parameterise the utility functions (assumed separable and identical in family consumption) and consider the process whereby the couple agree on how to spend a given amount of lifetime family income, and then each spouse chooses $R^{* j}$ to maximize own utility, given the leisure preferences of the other spouse. Gustman and Steinmeier (2000) propose a solution algorithm with each spouse choosing their own labour supply to maximize own utility while knowing the leisure preference of their partner, while cooperating to select the Nash equilibrium that is advantageous to both.

Several general properties of the solution can be readily derived. An increase in the AP eligibility age of women affects husband's retirement decision in two ways. First, the decline in $S S W$ due to a rise in $t_{q}^{w}$ is a pure negative family wealth shock, leading to an increase in the husband's optimal retirement age (wealth effect) assuming leisure is a normal good. Second, given the husband's relative preference for shared retirement the husband will postpone retirement in response to the increase in his wife's optimal retirement age. A decline in $S S W$ leads to an increase in the optimal retirement age of the wife, reducing the relative value of the husband retiring prior to his spouse. The total effect of a change in the wife's APA on the husband's retirement choice $R^{h *}$ will depend on the combined magnitude of the wealth and shared leisure effects.

This model of the impact of a wife's AP age on her husband's retirement choice contains important simplifications. First, it is important to consider the operation of the means test. High income and wealth families who expect to be ineligible for the pension due to the means test will be unaffected by the AP reform. The means test also creates a potential link between labour supply and AP benefits via family income in each period beyond $t_{q}^{w}$. Further, liquidity constraints may limit a family's ability to move resources through time. An inability to borrow against future expected $S S W$ suggests that the AP reform will have a stronger impact on the retirement behaviour (and welfare) of illiquid low wealth families. These additional factors will be considered in the empirical analysis. 


\section{DATA AND EMPIRICAL METHODS}

\subsection{Data and Descriptive Statistics}

Our empirical analysis is based on eleven cross sections (1994/95 to 2009/107) of the nationally representative Australian Bureau of Statistics Income and Housing Costs Surveys (IHCSs). The IHCSs were conducted on a sample of households throughout Australia during a given fiscal year (for example, from July 1994 to June 1995). Our eleven cross sections overlap 17 calendar years from 1994 to 2010. Pooling the cross-sectional surveys provides a relatively large sample of observations for individuals in the age range of 60-69 years, on whom we focus for analyzing the spillover effects of AP reform. ${ }^{8}$

A limitation of the IHCS data is the lack of information on exact birth dates. The data contain information on the quarter in which the interviews occurred (September, December, March or June) and each individual's age at the time of the interview but not his or her precise birth date. Subtracting the age of each individual from the year and quarter of the interview provides a 15-month window for the birth dates of individuals. As a result, when we assign treatment group status based on birth years, there is potential for misclassification. Similar to Card and Krueger (1992) and Mastrobuoni (2008), we address this issue by assuming that 'quarter of birth' is uniformly distributed ${ }^{9}$ over a year, which gives us a known probability of misclassification which we incorporate into the estimation.

Another limitation of the data is that information in some dimensions is coarse. In particular, age is a categorical variable after 64 years; thus, we have a continuous age variable until age 64 and a grouped variable indicating whether an individual is in the age range of 65-69 years. ${ }^{10}$ As part of the sensitivity analysis we restrict the sample to 60-64 year old men to ensure that the results are not sensitive to this measurement issue.

\footnotetext{
${ }^{7}$ There is no publicly released IDHC Survey for the fiscal years 1998/99, 2001/02, 2004/05 and 2006/07.

${ }^{8}$ The empirical model is only able to identify one-sided leisure complementarities; the effect of wife's choices on hushand's decisions. This can be rationalised by the theoretical model either with asymmetries in the leisure complementarities of partners, or a first-mover advantage to women who historically face a lower APA than men. This modelling restriction is supported by the findings of Coile (2004) and Gustman and Steinmeier $(2000,2004)$ who report husbands' timing of retirement to be responsive to their wife's retirement, while women's retirement timing is at most weakly related to their husband's retirement.

${ }^{9}$ This distribution is consistent with birth registry data. Payment record data also confirm that the incidence of Age Pension receipt is uniform across month of birth; there is no seasonality in the probability of pension receipt by month of birth.

${ }^{10}$ The grouping of age is not a problem for defining the female cohorts as we focus on women aged 60-64 years.
} 
The main variable of interest in the analysis is retirement status. In all IHCS data sets, there is a variable that indicates labour force status at the time of each interview. We classify people who report that they are "not in the labour force" as retired, and the remainder are classified as participating in the labour force.

Our main sample is composed of men aged 60 to 69 years who are married to women aged from 60 to 64 years, though we consider broader samples in the sensitivity analysis. The main sample represents the set of families in which women are at risk of retirement and most likely to be affected by the AP reform. The sample contains 3,071 families where the wife was born between 1929 and 1950. The sample includes a cohort unaffected by the AP reform due to the wife being born between 1929 and July 1935, which forms the control group for the main analysis.

Table 1 presents the summary statistics for the main sample. The top panel presents selected characteristics of men by their spouse's birth cohort. The lower panel presents selected characteristics of the married women by their own birth cohort. Participation rates are higher for more recent cohorts, and for married men relative to their partners; however, the gender difference in participations rate is substantially less for the most recent birth cohort. Comparing across columns, one feature is the increase in the attainment of Bachelor degrees among more recent birth cohorts. The difference in educational attainment between men and women diminishes with more recent cohorts. The incidence of home ownership is high (92-93\%) and similar for each cohort. The last two columns of Table 1 summarise the characteristics of samples which contain two alternative control groups. The first extends the main sample by including men with a wife aged between 65 to 69 years, and the second is restricted to single men aged 60-69 years. These two samples have similar characteristics on average to the main sample, although the singles sample is younger and less educated. We control for the characteristics reported in Table 1 in all the following analysis. 


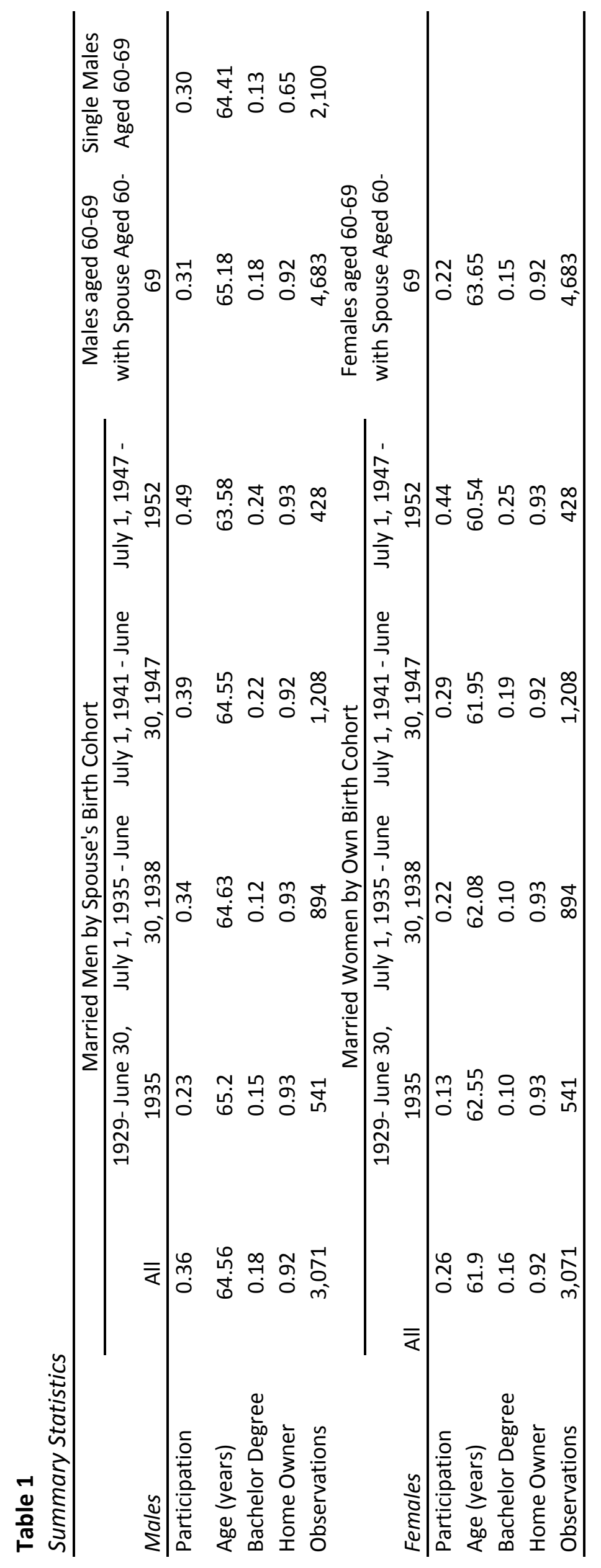


With regard to retirement trends, Figure 2 depicts the labour force participation rates over time for men and women in Australia between the ages of 60 and 69 years. The solid lines for men and women plot aggregate time series data from the Australian Bureau of Statistics Labour Force Survey, and the connected lines plot calculations based on the IHCS data. Our sample of pooled cross sections replicates the aggregate trends. This figure shows that the labour force participation rates of older women in Australia have increased substantially over the last two decades. Since the mid-1980s, the labour force participation rates of men display a similar trend to that of women. The figure incudes plots of labour force participation rates by marital status. An increase in female participation rates occurs for both married and single women. However, this trend does not apply to the participation rates of men. In particular, the participation rates of single men remain fairly constant through the last decade, in contrast with the increasing participation rates for married men.

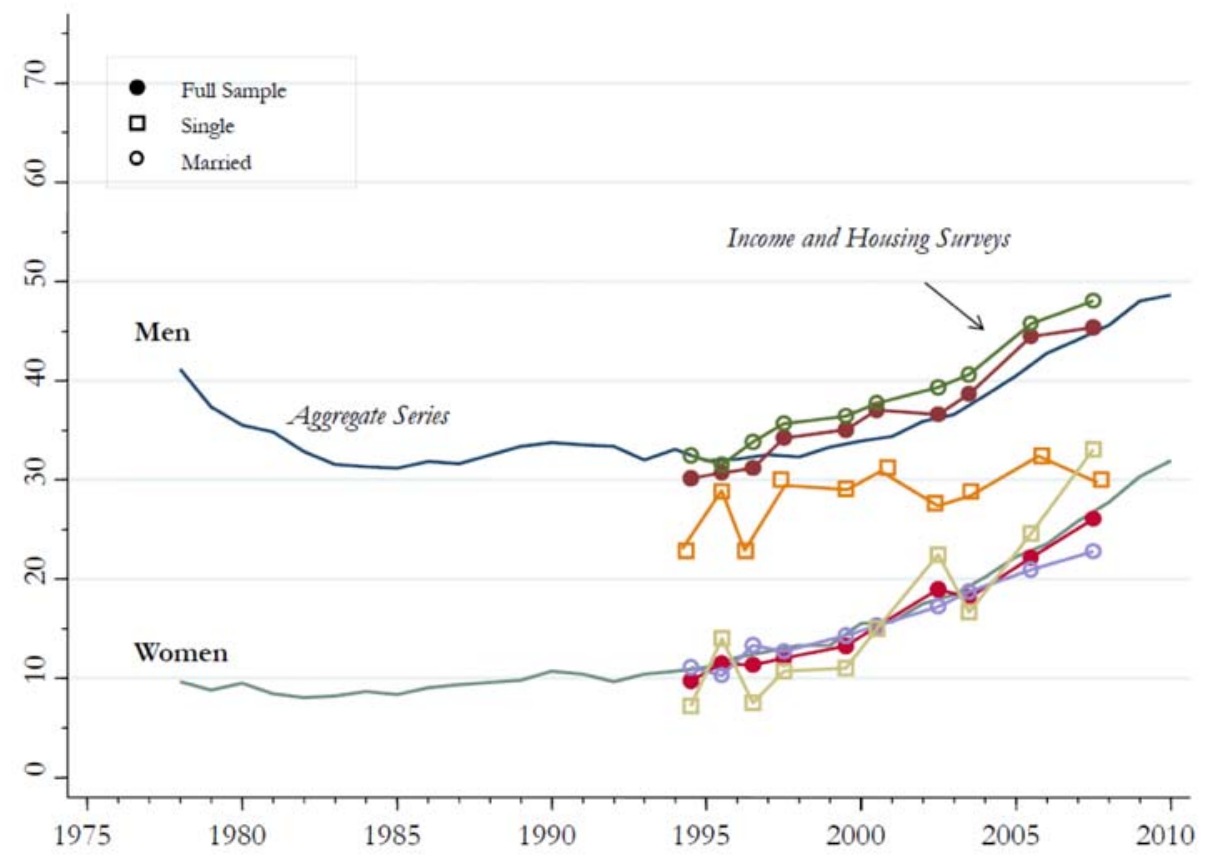

Figure 2.

Participation Rates of Individuals Aged 60-69 Years by Gender 
For the AP reform to generate spill-over effects on married men's participation, first we must demonstrate that the reform directly increased the labour force participation of married women. Figure 3 shows the participation rates by age for selected birth cohorts of married men and women in our sample. For women, each cohort encounters a different pension eligibility age. Figure 3 shows that the labour force participation rates of the more recent cohorts of women are substantially higher than those of the earlier cohorts. Another important trend from this figure is that, contrary to the finding for married women, there are no cohort differences across the married male birth cohorts defined by own birth date.

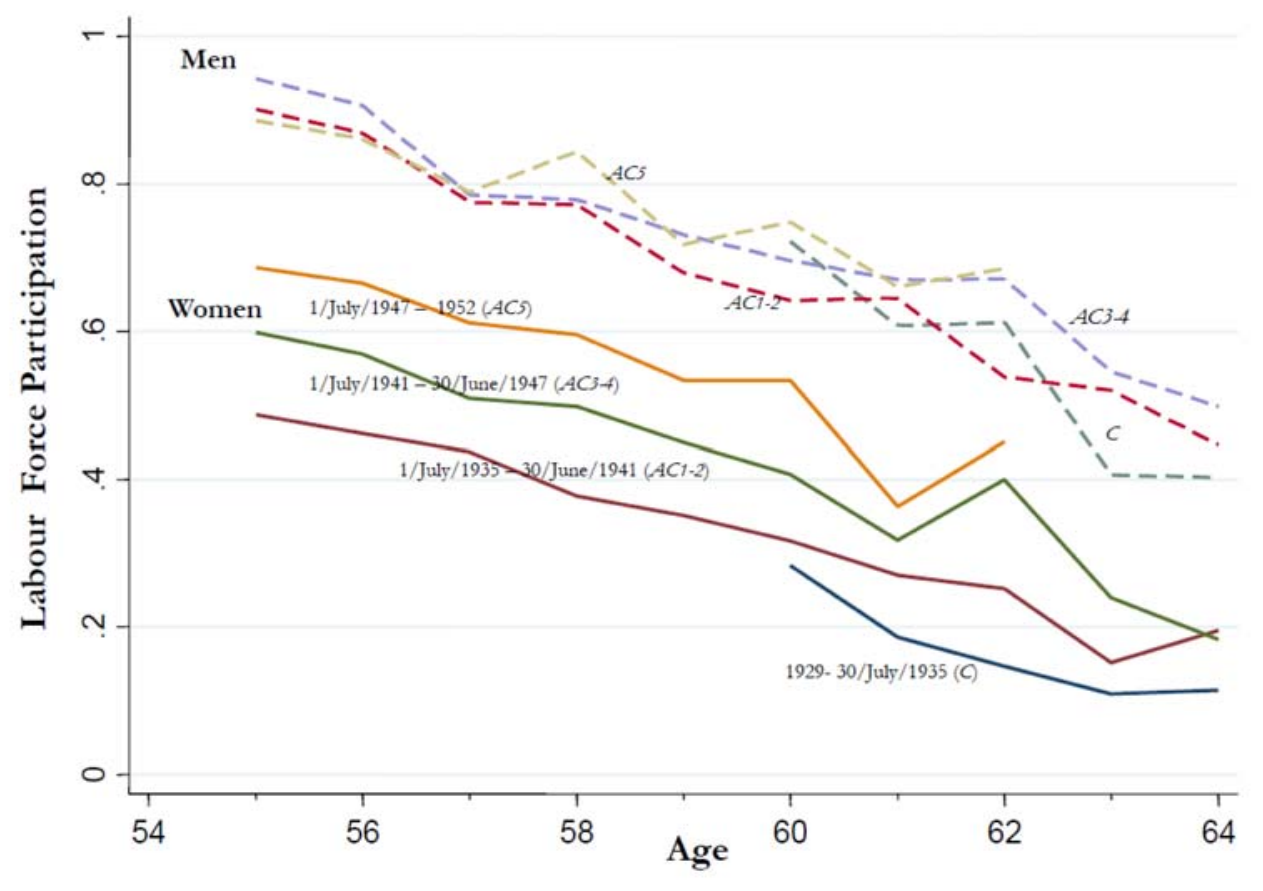

Figure 3.

Participation Rates of Married Men and Women, by Birth Cohort 
To further investigate differences in the participation rate of married women by birth cohort, we estimate a linear probability model for labour force participation using the specification:

$$
W i f e L F P_{i}=\beta X_{i}+\sum_{k=60}^{64} \alpha_{k} A g e_{k i}+\sum_{k=60}^{64} \sum_{j=1}^{5} \delta_{j k} A g e_{k i} \times \operatorname{Pr}\left(A C_{j i}^{*}=1\right)+u_{i}
$$

where a married woman's labour force participation $W$ ife $L F P_{i}$ is an indicator variable that equals 0 if individual $i$ is retired and equals 1 if the individual participates in the labour force. The vector $X$ is a set of control variables that includes education, state of residence dummies and family size, $A g e_{k i}$ is a set of age indicators for woman $i$ and $\operatorname{Pr}\left(A C_{j i}^{*}=1\right)$ is the probability that woman $i$ belongs to birth cohort $A C_{j}^{*}$ impacted by the program reform. ${ }^{11}$ Five affected birth cohorts are identified: $A C_{1}^{*}$ for who the eligibility age is 60.5 61 (those born between 01/07/1935 and 30/6/1938); $A C_{2}^{*}$, for whom the eligibility age is 61.5-62 (those born between 01/07/1938 and 30/06/1941); $A C_{3}^{*}$ for whom the eligibility age is 62.5-63 (those born between 01/07/1941 and 30/06/1944); $A C_{4}^{*}$ for whom the eligibility age is 63.5-64 (those born between 01/07/1944 and 30/06/1947); and $A C_{5}^{*}$ for whom the eligibility age is 64.5-65 (those born after 01/07/1947). All of the age indicator variables are included (the constant term is suppressed), and the cohort born prior to 01/07/1935 form the reference cohort. The coefficient $\delta_{j k}$ measures the difference in the likelihood of being in the labour force for women in cohort $A C_{j}^{*}$ at age $A g e_{k}$ relative to the control group conditional on the observed covariates. This strategy is analogous to the specification and identification strategy used by Mastrobuoni (2009) in studying the reforms to the Normal Retirement Age in the US. Since more recent cohorts of women face higher APAs, we expect increasing labour force participation at older ages for more recent cohorts. For example, for women who were born after 01/07/1944, we expect higher labour force participation at ages 60-64 years. Full results are reported in the Appendix Table 1.

Table 2 reports the sum of the coefficients on the age indicators for each birth cohort for the sample of couples are both members are aged 6-0-64 years. The estimates imply that a hypothetical 1-year increase in the AP eligibility age induced an approximate 22 percent increase in married women's likelihood of labour force participation. The second

\footnotetext{
${ }^{11}$ We additionally check our main results by restricting our sample to observations for which the probability of misclassification is 0. Although the sample size decreases by half, our main results are robust to this specification. Tables with the full set of results are available upon request.
} 
column of the table uses the same specification for married men, with the cohorts defined by men's own birth date, to assess differences in participation rates across the male birth cohorts. The results indicate that although married men exhibited time trends that are similar to those of women (as seen in Figure 2), the effects are smaller and less statistically significant. Even so, the point estimates for cohorts AC3 and AC4 are large. With this more homogenous sample of married men (both partners are aged 60-64 years), there is a high correlation between the age, and birth cohort, of spouses and hence these estimates may partly reflect spill-over effects. A cleaner placebo test is presented in the third column which contains estimates for the same specification based on the sample of single males aged 60-64 years; it is clear that the male cohort effects are highly insignificant. 


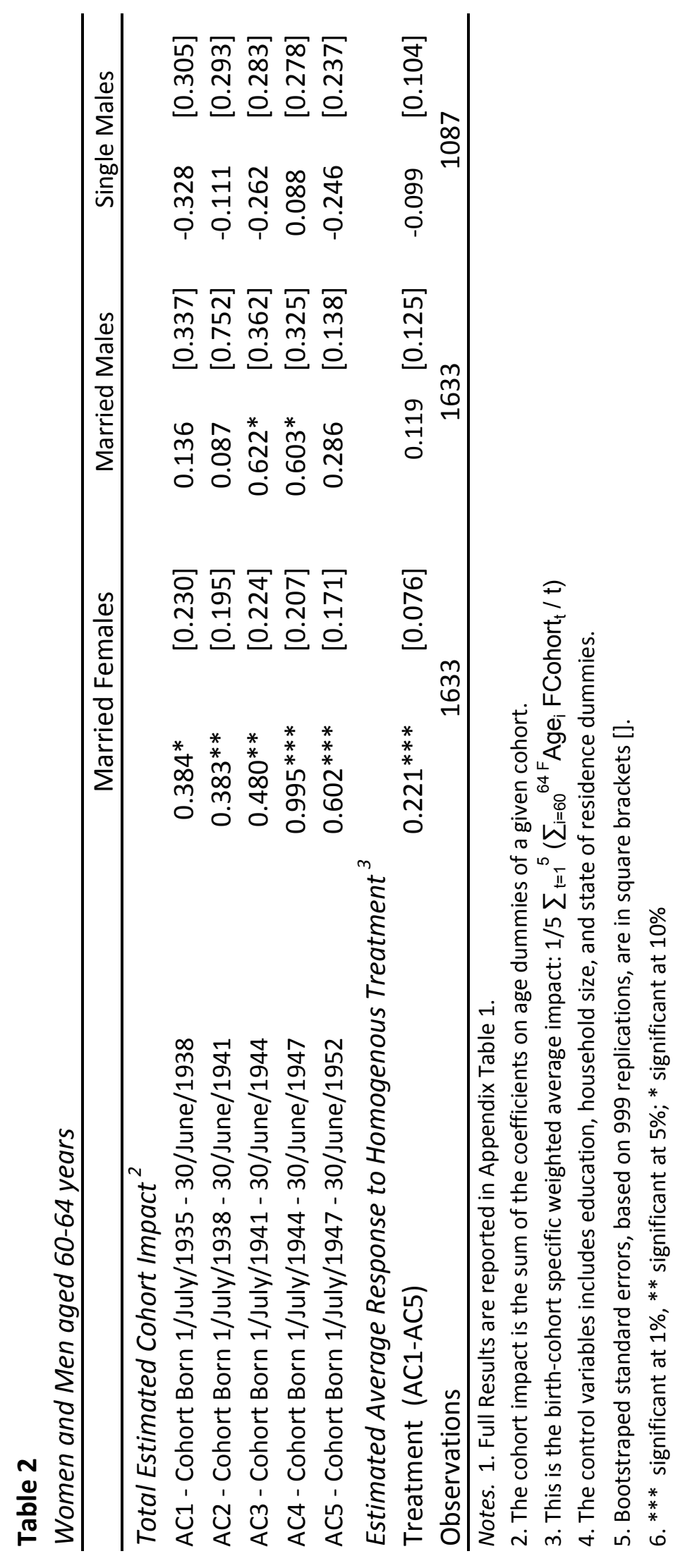




\subsection{Empirical Methodology}

The objective is to examine how the labour force behavior of married males is affected by the AP reform affecting their wife's access to the pension. Our empirical strategy is to compare changes in the retirement behavior of men with a spouse affected by AP reform to the behavior of men of the same age (and same spousal age) who are not affected by the reform because of their respective wife's birth date. In order to eliminate unobserved group-specific trends and time effects that have heterogeneous effects across married males, we primarily focus on the control group composed of married men aged 60-69 with a spouse born before July 1, 1935. However, to assess the robustness of the results, we consider additional control groups consisting of (i) single men aged 60-69, and (iii) couples where the wife is aged 65-69 and hence age eligible for the AP.

We begin our analysis by estimating a linear probability model ${ }^{12}$ of the labour force participation of men (MaleLFP $P_{i}$ equals 0 if male $i$ is retired) on individual, spousal and family characteristics, including dummy variables for age, education, family size, state of

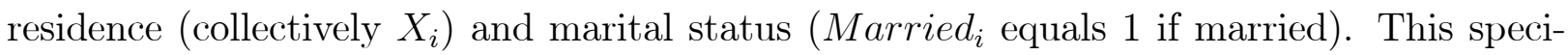
fication compares the labour force participation of single and married men of similar ages (analogous to Figure 2). We add interaction terms to the specification to capture the AP spill-over effects. In particular, the interaction between the Married $_{i}$ indicator and the indicator variable $A P R_{i}^{*}$ that equals 1 if the individual's wife is affected by the AP reform (i.e. born after $01 / 07 / 1935)$ is created:

$$
\text { MaleLFP }_{i}=\beta X_{i}+\alpha_{0} \text { Married }_{i}+\alpha_{1}\left[\text { Married }_{i} \times A P R_{i}^{*}\right]+u_{i}
$$

In equation (3), the control group consists of single men and married men with spouses who were born before 1/07/1935; hence, $\alpha_{1}$ captures the difference in $L F P_{i}$ between married men with spouses born after 1/07/1935 (treatment group) and men in the control groups, conditional on $X_{i}$.

The base model specifications estimates a mean effect across the affected cohorts. Given magnitude of the treatment varies by wife's birth cohort, it is useful to extend the specification to allow the estimated treatment effect to vary by partner's birth cohort. The baseline

\footnotetext{
${ }^{12}$ We obtain very similar results using the probit estimator. The probit results are available on request.
} 
specification (3) is extended by substituting the probability of having a spouse born after June 1935 with a series of variables reporting the probability of the spouse being in a specific birth cohort. For the extended analysis, we use the same female birth cohorts as defined in section 3.1. This model specification is given by the following:

$$
\text { MaleLFP }_{i}=\beta X_{i}+\alpha_{0} \text { Married }_{i}+\sum_{k=1}^{5} \alpha_{k}\left[\text { Married }_{i} \times \operatorname{Pr}\left(A C_{k i}^{*}=1\right)\right]+u_{i}
$$

We must determine whether $\alpha_{1}$ represents a spill-over effect from the retirement incentives of married women rather than arising from heterogeneous effects related to marital status.

We conduct further analysis based only on the sample of married males. To allow for age-specific shifts in the work propensities of married men, we apply a differences approach that is similar to equation (2); we control for the age of husbands (MAge) and interact this with the female spouse's birth cohort variables $\left(A C^{*}\right)$. We additionally control for the age of the spouse, the education of both husband and wife, family size and state of residence ${ }^{13}$ :

$$
\text { HusbandLFP } P_{i}=\beta X_{i}+\sum_{k=60}^{69} \alpha_{k} M A g e_{k i}+\sum_{k=60}^{69} \sum_{j=1}^{5} \delta_{j k}\left[M A g e_{k i} \times \operatorname{Pr}\left(A C_{j i}^{*}=1\right)\right]+u_{i}
$$

All of the age dummy variables for married men are included (the constant term is suppressed), and the birth cohort variable for wife born before $01 / 07 / 1935$ is omitted. The $\delta_{j k}$ coefficient measures the difference in the likelihood of being in the labour force for men with a spouse belonging to cohort $A C_{j}^{*}$ at age $M a g e_{k}$ relative to the control group (men with spouses who were born before July 1935 in this model) conditional on observed covariates.

There may be a remaining concern with the common trend assumption (the treatment and control group similarity) in our difference strategy. As illustrated in Table 2, the treatment groups (married men with a spouse born after July 1, 1935) are similar to the control group (married men with a spouse born before July 1, 1935); however, they may differ in unobserved ways. Consequently there may be other group specific trends in labour market behavior not the result of AP reform affecting the labour supply decision of elderly men. This could be due to other policy reforms differentially affecting this group. Apart from the APA change, there were no social security or labour regulation changes that affected the 60-69 age group of men during our observation period. Nevertheless, as an alternative

\footnotetext{
${ }^{13}$ Note that this specification effectively controls for the age difference between spouses as the age of both members of the couple are included.
} 
strategy, we re-estimate the labour force participation equations with a different potential control group. We augment the sample by including married men with a spouse aged 65 to 69. Women over age 65 are age eligible for the AP regardless of their birth cohort. Note that some of the women over age 65 were potentially impacted by the APA, and there may have been an adjustment to employment over time due to the wealth effect. Although it is unlikely this specification eliminates all concerns regarding the identification, it does provide another assessment of the robustness of our findings through consideration of another control group. The specification used with this expanded sample is:

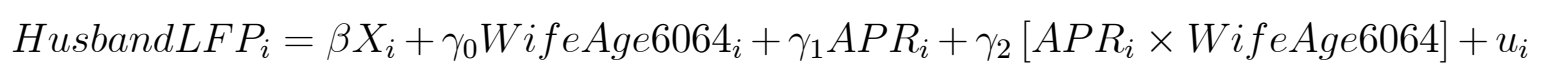

where WifeAge6064 $i$ is an age group dummy that takes the value 1 if the male's wife is aged 60 to 64, and 0 if his wife is aged 65 to 69. This strategy compares the change in the labour supply of married men with a spouse aged 60-64 years (treatment groups) to those with spouses aged 65-69 years (control group) under the assumption that they would experience the same changes in the labour supply in the absence of AP reform.

\section{RESULTS}

The first column of Table 3 shows that married men are 5 percentage points more likely to participate in the labour force compared with the single men in our sample. When we estimate equation (3), as reported in column 2 of Table 3, we observe that this difference is primarily driven by men with a spouse affected by the AP reform. After controlling for the education and age, men with a spouse affected by the reform are approximately 7.3 percentage points ${ }^{14}$ more likely to participate in the labour force than single men. By the same token, conditional on education and age, married men with a spouse affected by the reform are approximately 16.1 percentage points ${ }^{15}$ more likely to participate than married men with a spouse unaffected by the pension reform. The third column of Table 3 allows for heterogeneous effects by wife's birth cohort (equation 4). The estimates clearly show responses in line with the differing treatment intensities. In particular, the treatment effects of the APA are more pronounced for men married to women from the more recent birth

\footnotetext{
${ }^{14}$ Which is calculated as $\hat{\alpha}_{0}+\hat{\alpha}_{1}$.

${ }^{15}$ Which is calculated as $\hat{\alpha}_{1}-\hat{\alpha}_{0}$.
} 
cohorts. This finding is consistent with the magnitude of the family wealth effect of the APA changes. A potential threat to the internal validity of these results is that single men, who compose part of the control group, may differ from their married counterparts in unobservable ways; thus, single men may not constitute an appropriate comparison group. To address this criticism, we restrict our sample to married men in the remaining analysis.

Table 4 presents the estimates from equation (5), which allows for age-specific differences in the labour force participation response by husbands for each spousal birth cohort. This is the most general specification of the treatment effect based on the preferred identification strategy. The identification assumption for this model is that, conditional on the observable characteristics of couples, cohort differences in the participation rates of married men are driven by the APA reform impacting their wife. This specification also enables us to evaluate the heterogeneous effects by married men's own age and their partner's birth cohort. ${ }^{16}$ Table 4 presents two summary panels: Panel A aggregates the estimated effects with respect to wife's birth cohort and Panel B aggregates the estimated effects according to the male's age. Estimates are presented for four subsamples. Columns (1) and (2) contains the results for married men aged 60-69 years with a spouse aged 60 to 64 years. For columns (3) and (4) we restrict the sample to males aged 60-64 years with a wife aged 60-64 years. For models in columns (2) and (4), we further restrict the sample to couples where the husband is older than his wife. By virtue of being older, the husband is closer in age to the male APA of 65 , and hence may be more responsive to this wife's pension incentives and participation decision.

\footnotetext{
${ }^{16}$ Full results are reported in the Appendix Table 2.
} 
Table 3

Regression Adjusted Difference in Difference Estimates, Males ${ }^{1}$

Male Participation
Warried
Wife born after July/1935
1/July/1935 - 30/June/1938
1/July/1938 - 30/June/1941
1/July/1941 - 30/June/1944
1/July/1944 - 30/June/1947
1/July/1947 - 30/June/1952

Age 60-69

[0.013]

$\mathrm{Ag}$

Age 60-69

$-0.044$

[0.027]

$0.117^{* * *}$

[0.021]

$[0.021]$

Education:

\begin{tabular}{lccc} 
Bachelor & $0.160^{* * *}$ & $0.157^{* * *}$ & $0.153^{* * *}$ \\
Other Non-School Qualifications & {$[0.019]$} & {$[0.019]$} & {$[0.019]$} \\
& $0.030^{* *}$ & $0.028^{* *}$ & $0.030^{* *}$ \\
Homeowner & {$[0.015]$} & {$[0.014]$} & {$[0.014]$} \\
& $0.038^{* *}$ & $0.038^{* *}$ & $0.037^{* *}$ \\
Male Age: & {$[0.017]$} & {$[0.016]$} & {$[0.017]$} \\
60 years & & & \\
& $0.354^{* * *}$ & $0.347^{* * *}$ & $0.343^{* * *}$ \\
61 years & {$[0.026]$} & {$[0.026]$} & {$[0.026]$} \\
& $0.296^{* * *}$ & $0.288^{* * *}$ & $0.285^{* * *}$ \\
62 years & {$[0.024]$} & {$[0.024]$} & {$[0.024]$} \\
& $0.239^{* * *}$ & $0.233^{* * *}$ & $0.230^{* * *}$ \\
63 years & {$[0.023]$} & {$[0.023]$} & {$[0.022]$} \\
& $0.222^{* * *}$ & $0.218^{* * *}$ & $0.217^{* * *}$ \\
64 years & {$[0.021]$} & {$[0.020]$} & {$[0.020]$} \\
& $0.149^{* * *}$ & $0.147^{* * *}$ & $0.145^{* * *}$ \\
Constant & {$[0.020]$} & {$[0.020]$} & {$[0.022]$} \\
& $0.112^{* * *}$ & $0.116^{* * *}$ & $0.117^{* * *}$ \\
Adjusted R-squared & {$[0.015]$} & {$[0.016]$} & {$[0.015]$} \\
Observations & 0.099 & 0.104 & 0.107 \\
\hline
\end{tabular}

1. The sample contains married males aged 60 to 69 with spouses aged 60 to 64 and single males aged 60 to 69

2. All regression includes indicators for state of residence and a variable for household size.

3. Bootstraped standard errors, based on 999 replications, are in square brackets [].

4. ${ }^{* * *}$ significant at $1 \%,{ }^{* *}$ significant at $5 \% ;{ }^{*}$ significant at $10 \%$

0.048

[0.031]

$0.108^{* * *}$

[0.028]

$0.085^{* * *}$

[0.026]

$0.139 * * *$

[0.025]

$0.172^{* * *}$

[0.031]

0.153***

[0.019]

0.030 **

$0.037 * *$

[0.017]

[0.026]

$285^{* * *}$

$0.230 * * *$

[0.022]

$0.217^{* * *}$

$145 * *$

[0.022]

$0.117 * *$

[0.015]

0.107

5,171 

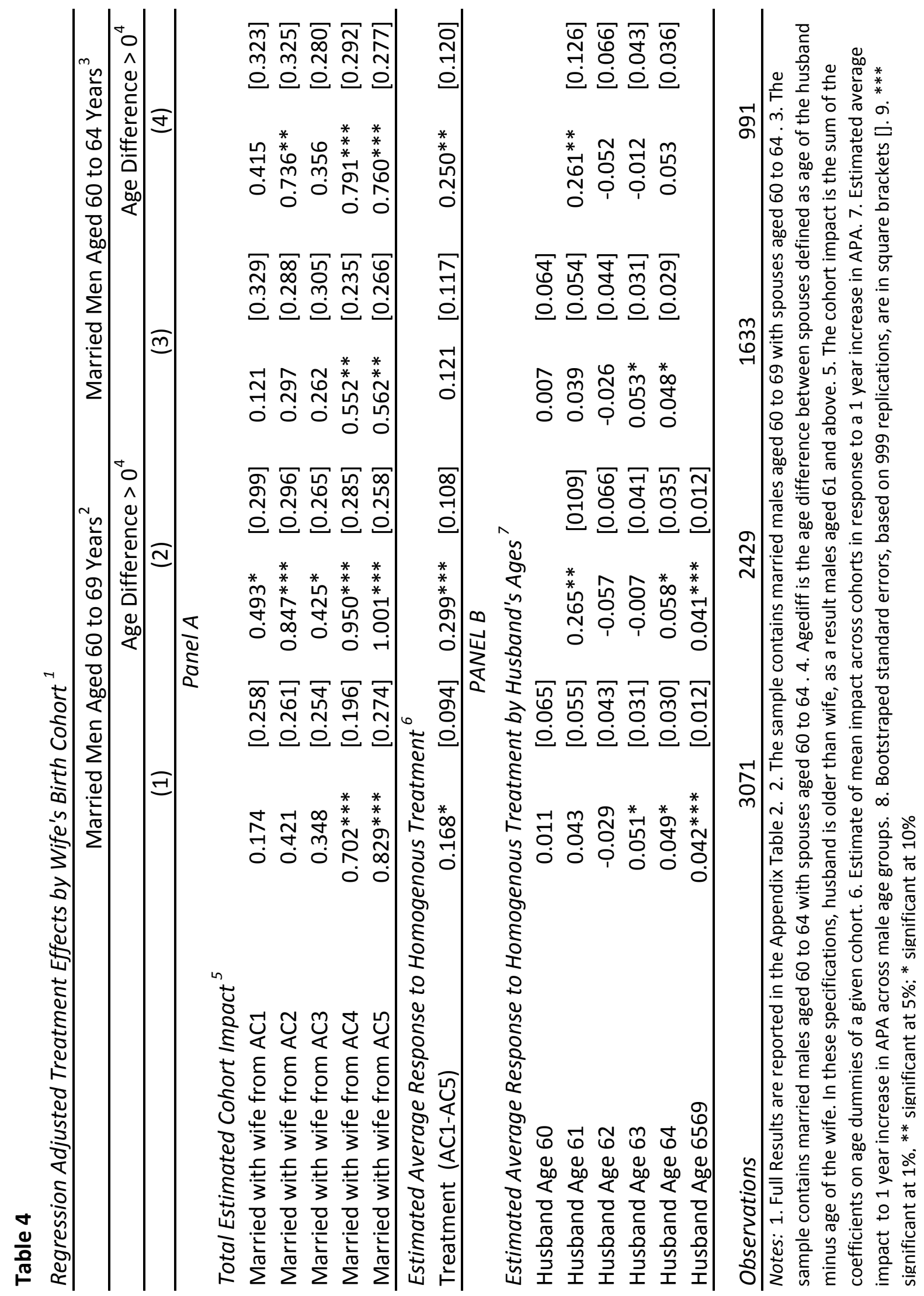
There are two important patterns revealed by the results shown in Table 4, column (1). First, similar to the specifications in Table 3, we observe that the treatment effects of the APA are more pronounced for men married to women from more recent birth cohorts. In fact, the results for men with a spouse born between 1/July/1935 and 30/June/1944 are not significantly different from the results for the men with a spouse born before 1/July/1935. Second, the treatment effect is more pronounced for older married men. In particular, men over 62 years of age married to a woman affected by the AP reform report significantly greater participation, while men aged 62 and younger do not. In addition, the 65-69 age group of husbands report significant increases in their participation compared with men of the same age in the control group. This increase is important since this group of men are age qualified for AP benefits regardless of the APA facing their wife. This finding supports the hypothesis that AP reform affects men through their preference for joint leisure, the 'complementarity of leisure effect'. To aid the interpretation, and provide comparability with the difference results, we follow the calculations of Mastrobuoni (2008) and aggregate these coefficients into a summary statistic, the weighted average effect across cohorts $\frac{1}{5} \sum_{k=1}^{5}\left(\sum_{j=60}^{64 / 69} \delta_{\text {AAge }_{j} \text { ACohort }_{k}} / k\right)$. This statistic is the average response to a hypothetical uniform 1-year increase in the APA and is reported under the panel A of Table 4. We find that the APA increases led to an average 16 percentage point increase in labour force participation of married men aged 60 to 69 with a spouse in the affected cohorts, and 12 percentage point increase for the subgroup of married men aged 60 to 64 . The magnitude of the estimates are similar to our findings from the previous specifications, though the significance levels are smaller. Specifically, for the latter 60-64 year age group, the total effect is not statistically significant. When we restrict our sample to families in which husbands are older than their wife, the reform has even larger impacts which are highly statistically significant. This is not surprising as in these subsamples the husband is closer to his own APA and may be more flexible in adjusting his participation in response to his wife's pension incentives.

Table 5 presents the estimated difference in the change of labour participation between married men with a wife aged 60-64 years and those with a wife aged 65-69 years. Women in the former group are subjected to the AP reform, depending on their birth date. Women 
between ages 65 and 69 years are age-eligible for the AP regardless of their birth date and hence the spill-over effects of AP reform on men with a spouse aged 65 to 69 may be more muted as the current income and liquidity constraint effects no longer apply. However, the family wealth effects of later AP eligibility may impact labour supply (and consumption) profiles beyond the APA and hence husbands of women aged 65-69 years are not an ideal control group. Equation (6) exploits this identification strategy and is presented here as a robustness check, providing a lower-bound estimator of the treatment effect. The coefficient of the treatment group identifier (spouse aged 60 to 64 ) is negative but insignificant, and the coefficient of the after-cohort (Born after 1 July 1935) dummy variable is positive and significant. The interaction of the cohort and treatment dummy variables which captures the impact of policy reform, is positive and statistically significant at the 5 percent level. Our results show that this difference-in-difference estimate of the APA reform on the cohorts of affected women at the affected ages led to a significant increase in married men's LFP of approximately 7 percent on average. In the second column of the Table 5, we estimate equation (5) with additional covariates, including year dummies and home ownership status, to check robustness of the results in column (1) to time and group effects. We find that although the positive cohort effect disappears, the reform treatment effect is close to our base specifications (3) of the average effect across treated cohorts (reported in Table 3, model 2), and is statistically significant. 


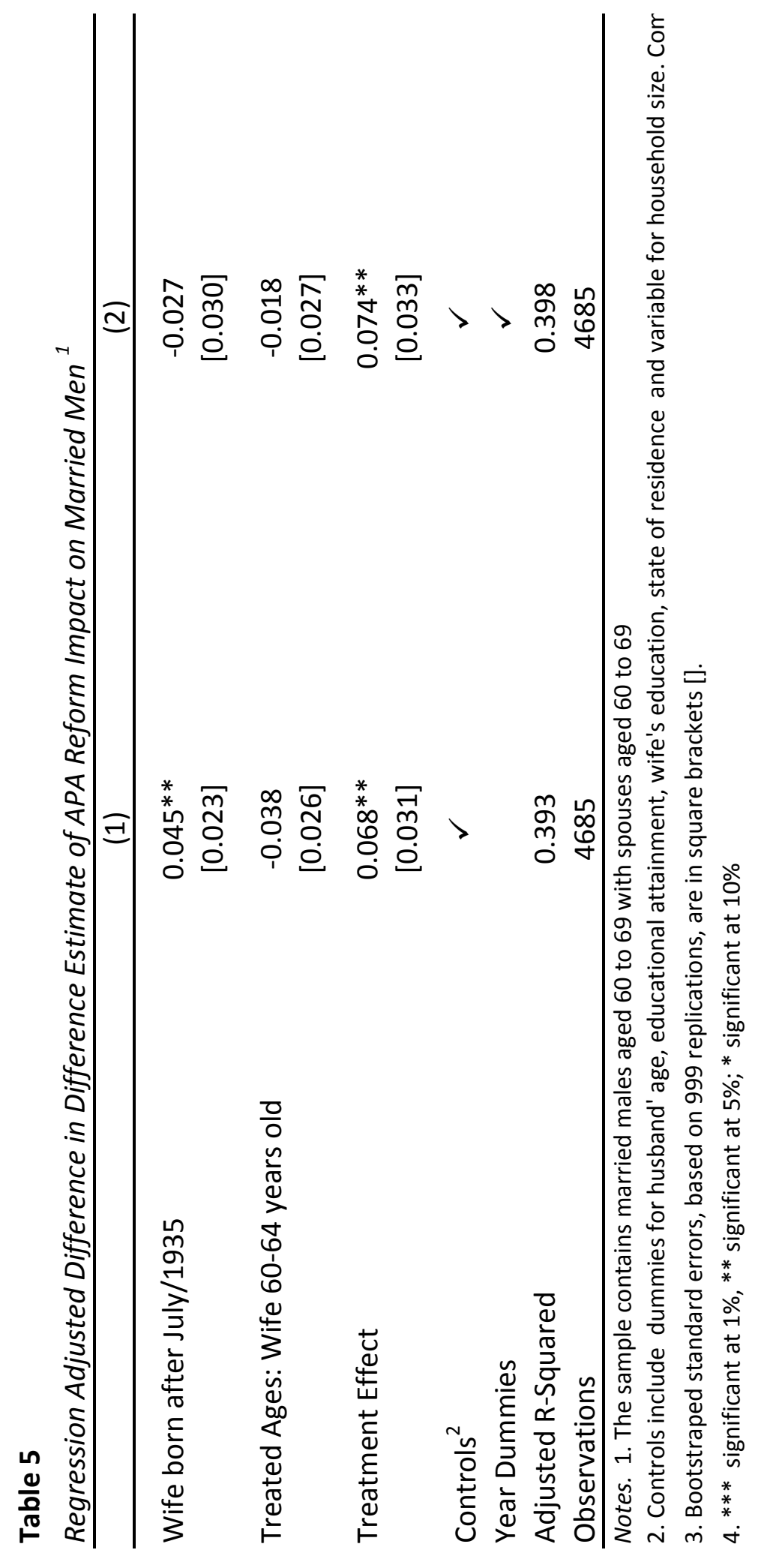




\subsection{Alternative Estimator}

As a further check on the robustness of the empirical results, an instrumental variables estimator of the effect of a wife's participation on their husband's decision was considered. Following Banks et al. (2010) and Schirle (2008), the couple's participation decision may be modelled as

$$
\text { HusbandLFP } P_{i}=\beta X_{i}+\gamma W i f e L F P_{i}+v_{i}
$$

The wife's labour force participation is endogenous due to, for example, correlated preferences with assortative matching. The APA faced by the wife represents a potential instrumental variable. This instrumental variable strategy uses the variation in married women's labour force participation over ages 60-64 years that is colinear with the legislated increase in the APA to identify the husband's labour supply response. ${ }^{17}$ The IV estimator captures a local average treatment effect where $\gamma$ measures the mean response of the policy relevant group of 'compliers' - husbands of the women who increased their participation in the labour force due to the rising APA.

The IV estimate $\hat{\gamma}$ for the full sample of husbands aged $60-69$ years is $0.716(0.145)$ compared to the OLS estimate of $0.436(0.019)$. Due to the imprecision of IV estimator, the 95 percent confidence interval for the IV estimator includes the OLS estimates. For the subset of husbands who are older than their partner, the IV and OLS estimates are 0.796 (0.186) and $0.458(0.022)$, respectively, indicating uniform effects across the subsample. The IV estimates are larger than the effects found for the UK, Canada and US by Schirle (2008) though it is important to note that our results apply for the broader population that is eligible for the Australian AP program.

\subsection{Alternative Programs: Disability Support}

The Disability Support Pension (DSP) has the highest participation rate of income support programs after the AP for families in our target age range. Like the AP, and unlike disability insurance programs in other countries, the Australian DSP program is non-contributory and eligibility is not tied to prior work history. The DSP benefit rate and means test is the same

\footnotetext{
17 The preliminary results presented in Table 2 demonstrate the relevance of this instrumental variable. The instrument validity condition is not directly testable.
} 
as that for the AP. To qualify for DSP an individual must be (i) under AP age, (ii) assessed as having severe physical, intellectual or psychological impairment, and (iii) unable to work at least 15 hours per week within a two year period. ${ }^{18}$ Conditional on being assessed as having a significant long term incapacity for work, the DSP program represents a potential substitute form of income support for individuals impacted by the AP reform. Atalay and Barrett (2015) show the rise in the APA had an unintended consequence of increasing enrolment in DSP by women in the affected cohorts. In this subsection we assess whether men whose wife faced a higher APA are less likely to use DSP, and whether the APA reform lead to a net change in DSP claiming behaviour at the family level. Since married men are found to have increased their labour force participation in response to the delayed retirement of their partner following the APA reform, we expect to see a decrease in married men's DSP enrollment. At the same them, DSP may function as an alternative income source for women disentitled from the AP program, and married women's DSP claiming may increase. Due to the competing effects, the net effect on DSP claiming at the family level is uncertain.

Specification (5) is used to study DSP take-up. In results not presented here ${ }^{19}$ the point estimates for spouse's birth cohort effects on husband's DSP take-up are negative and jointly significant (Wald test statistic of $41.38, p$-value $=0.019$ ). The estimated average response to a one-year increase in wife's APA is a -5.1 percentage points in DSP take up. This finding is consistent with positive leisure complementarities dominating within couples. It is apparent that the increase in the labour market participation of married women had further spillover effects on the program participation of their partner, which is often neglected in the welfare and budget calculations of program reform impacts.

Considering the impact of the APA increase on DSP take up at the family level, the estimated net effects on DSP participation is found to be generally negative with an estimated average 2.7 percent decline in response to a one-year increase in APA. ${ }^{20}$ This point estimates confirm the observed increase in female DSP counteract the male decrease in DSP take-up, results in the small negative net decline in DSP participation at the family level.

Overall, our results indicate that increases in the APA of women has been associated with

\footnotetext{
${ }^{18}$ DSP recipients are automatically transferred to the AP on becoming age-eligible.

${ }^{19}$ Full results are available in the online working paper.

${ }^{20}$ The wife's birth cohort effects on DSP takeup at the family level are jointly statistically significant as indicated by the Wald test statistic of 43.16 ( $p$-value $=0.009)$.
} 
an increase in the labour force participation of married women, leading to an increase in the labour force participation of men who are married to women in the affected cohorts combined with a small negative effect on the probability that families participated in alternative income support programs such as DSP.

\subsection{Aggregate Implications}

The economic significance of the within-family spillover effects in retirement behaviour may be gauged by considering the aggregate implications of the measured treatment effects. Estimates for the preferred model specification (5), presented in Table 4 are used to predict the labour force participation of married men aged 60-69 years, for a range of scenarios. Figure 4 plots the average predicted probability of labour force participation across the 17 calendar years covered by the sample of pooled cross-sections. As shown in Figure 4, the average model prediction closely tracks the raw sample average across the observation period, capturing the strong upward trajectory in the participation rate for this group of men, which increased from 0.30 to 0.49 between 1994 and 2010. The estimated model is then used to predict the probability of labour force participation for the hypothetical scenario that their wife's APA has remained constant at age 60 years. For this counterfactual, the within-family spillover effects are shut down, with the predictions based on the parameters estimates $(\hat{\beta}, \hat{\alpha})$ though the treatment effects turned off $\left(\check{\delta}_{j k}=0\right.$ for all $\left.j, k\right)$. The plot of the average simulated labour force participation rate shows a minor increase (from 0.30 to 0.36) over the observation period. The counterfactual participation rate is a substantial 13.2 percentage lower than the observed participation rate in 2010. The divergence between the observed and counterfactual participation rate grows over time due to the larger fraction of the sample of men being married to women who received the most intense treatment. 


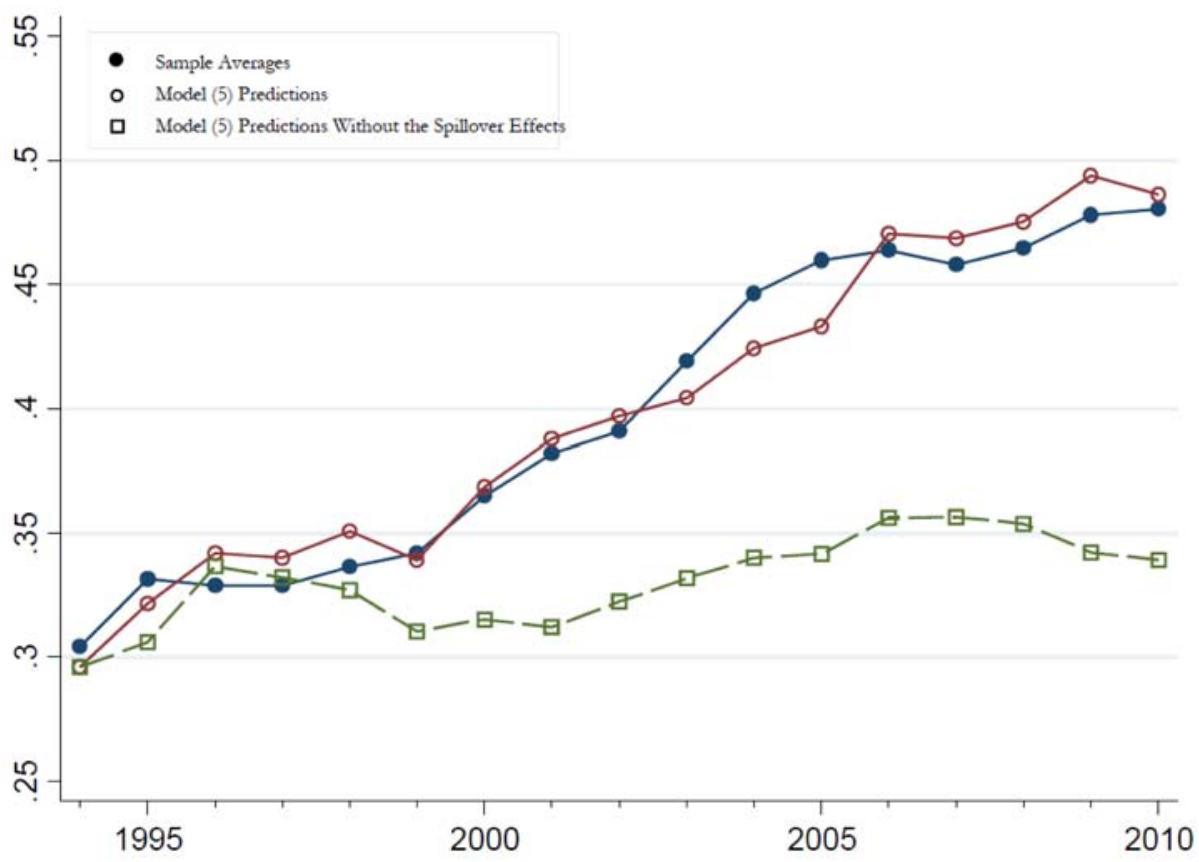

\section{Figure 4.}

Observed and Predicted Aggregate Labour Force Participation Rates, Married Men Aged 60-69 years, 1995-2010.

The implications of the within-family spillover effects are further highlighted by extrapolating the impact on participation rates for all men aged 60-69 years. By 2010 the within-family spillover effect of the APA reform was found to have increased the participation rate of men aged 60-69 years married to women in the affected birth cohorts by 36 percent. Given that 54 percent of married men in the age range in 2010 had a partner unaffected by the policy change, and that 24.5 percent of men in the 60-69 year age range were single, implies that the APA reform targeted at women increased the participation rate among all 60-69 year old men by approximately 12.5 percent. The aggregate implications of the within-family spillover effects reveal a substantial impact of the APA reform on male labour force productivity. 


\section{CONCLUSION}

Recent pension reforms in most countries have involved policies that aim to increase the labour force participation of elderly individuals (OECD 2011). Although models of joint retirement decisions emphasise the consideration of within-family spill-over effects when evaluating social security reforms, empirical studies have largely neglected this avenue of influence when assessing reform impacts. We study the 1993 AP reform in Australia which increased the eligibility age for women to access AP benefit payments. The change to the AP eligibility age represents a reduction in the social security wealth of the affected cohorts of women and their families, and provides a unique natural experiment in which to study the incentives of the AP program. We investigate the extent to which this policy reform induced a change in the labour force participation of married men.

Our results show that men with a spouse affected by AP reform increased their labour force participation. The magnitude of this spill-over effect is between 7 to 17 percentage points, varying according to the husband's age and wife's birth cohorts. Specifically, we find that, conditioning on spouse's age, the effect is more pronounced for men who are married to women from more recent birth cohorts for who the negative wealth effect shock is larger. The results also show that the spill-over effect is greater for men closer to their AP eligibility age. In addition, we find that men over the age of 65 who are age eligible for the AP also increased their labour force participation in response to their wife's delayed retirement. This finding highlights the significance of the shared leisure effect as an important factor in understanding the retirement decisions of couples. Overall, our results demonstrate the importance of considering spousal behavior when evaluating pension reforms.

\section{References}

Atalay, K., and G.F. Barrett (2015). "The Impact of Age Pension Eligibility Age on Retirement and Program Dependence: Evidence from an Australian Experiment," Review of Economics and Statistics, 97(1), 71-87.

Australian Bureau of Statistics (2009) Labour Force Historical Time Series, Canberra: Catalogue No. 6204.0.55. 
Baker, M. (2002) "The retirement behavior of married couples: Evidence from the spouse's allowance" Journal of Human Resources 37(1), 1-34.

Banks, J., Blundell R., and M. Casanova (2010) "The Dynamics of Retirement Behavior in Couples: Reduced-Form Evidence from England and the US" Working paper, Department of Economics UCLA.

Barrett G.F. and Y. Tseng (2008) "Retirement Saving in Australia" Canadian Public Policy, 34(1), 177-193

Blau, D.M. (1998) "Labor force dynamics of married couples" Journal of Labor Economics 16(3), 595-629.

Card, D., and A.B. Krueger (1992) "Does school quality matter? Returns to education and the characteristics of public schools in the United States," Journal of Political Economy $100(1), 1-40$.

Casanova, M. (2010) "Happy together: A structural model of couples' joint retirement choices" Working paper, Department of Economics UCLA

Coile, C. (2004) "Retirement Incentives and Couples' Retirement Decisions" Topics in Economic Analysis $\&$ Policy 4(1).

Cribb, J., Emmerson, C. and G. Tetlow (2013) "Incentives, shocks or signals: Labour supply effects of increasing the female state pension age in the UK", IFS Working Papers, No. W13/03

Danzer, A. M. (2013) "Benefit Generosity and the Income Effect on Labour Supply: Quasi-Experimental Evidence." Economic Journal 123(571), 1059-1084.

Gruber, J. and D. Wise (2004). Social Security Programs and Retirement Around the World: Micro Estimation, University of Chicago Press.

Gustman, A.L. and T.L. Steinmeier (2000) "Retirement in dual career families" Journal of Labor Economics, 18(3), 503-545.

Gustman, A.L. and T.L. Steinmeier (2004) "Social security, pensions and retirement behaviour within the family" Journal of Applied Econometrics, 19, 723-737.

Hanel, B., and R. T. Riphahn (2012) "The Timing of Retirement: New Evidence from Swiss Female Workers" Labour Economics, 19(5), 718-728

Hurd, M.D. (1990) "The joint retirement decision of husbands and wives" in Issues in 
the Economics of Aging, Wise, D.A. (ed). University of Chicago Press: Chicago

Mastrobuoni, G. (2008) "Labor supply effects of the recent social security benefit cuts: empirical estimates using cohort discontinuities," Carlo Alberto Notebooks, Collegio Carlo Alberto 2008.

Mastrobuoni, G. (2009) "Labor Supply Effects of the Recent Social Security Benefit Cuts: Empirical Estimates Using Cohort Discontinuities," Journal of Public Economics, 93(11-12), 1224-1233.

OECD (2011) "Pensions Incentives to Retire," in Pensions at a Glance 2011: RetirementIncome Systems in OECD and G20 Countries, OECD Publishing.

Selin, H. (2012) "What Happens to the Husband's Retirement Decision when the Wife's Retirement Incentives Change ?" CESifo Working Paper No. 3772.

Schirle, T. (2008) "Why have the labor force participation rates of older men increased since the mid-1990s?" Journal of Labor Economics, 26(4), 549-594.

Staubli, S., and J. Zweimüller (2013) "Does Raising the Retirement Age Increase Employment of Older Workers?" Journal of Public Economics, 108, 17-32.

Stancanelli, E. (2012) "Spouses' Retirement and Hours of Work Outcomes: Evidence from Twofold Regression Discontinuity", IZA DP 6791, August 2012

Vestad, O.L. (2013) "Labor supply effects of early retirement provision" Labour Economics, 25, 98-109.

Zweimüller, J, Winter-Ebmer, R., and J. Falkinger (1996) "Retirement of spouses and social security reform" European Economic Review, 40, 449-472. 


\section{Appendix Table 1}

Married Women's LFP

\begin{tabular}{lcc} 
AC1 (eligibility age 60.5 to 61) x (Age 60) & $0.200^{* *}$ & {$[0.101]$} \\
AC1 x (Age 61) & -0.029 & {$[0.100]$} \\
AC1 x (Age 62) & 0.006 & {$[0.079]$} \\
AC1 x (Age 63) & $0.178^{*}$ & {$[0.099]$} \\
AC1 x (Age 64) & 0.0289 & {$[0.114]$} \\
AC2 (eligibility age 61.5 to 62) x (Age 60) & $0.169^{*}$ & {$[0.101]$} \\
AC2 x (Age 61) & -0.023 & {$[0.092]$} \\
AC2 x (Age 62) & 0.094 & {$[0.074]$} \\
AC2 x (Age 63) & 0.014 & {$[0.071]$} \\
AC2 x (Age 64) & 0.129 & {$[0.094]$} \\
AC3 (eligibility age 62.5 to 63) x (Age 60) & $0.189^{* *}$ & {$[0.089]$} \\
AC3 x (Age 61) & 0.007 & {$[0.085]$} \\
AC3 x (Age 62) & $0.136^{*}$ & {$[0.081]$} \\
AC3 x (Age 63) & 0.026 & {$[0.094]$} \\
AC3 x (Age 64) & $0.122^{*}$ & {$[0.087]$} \\
AC4 (eligibility age 63.5 to 64) x (Age 60) & $0.342^{* * *}$ & {$[0.097]$} \\
AC4 x (Age 61) & 0.016 & {$[0.089]$} \\
AC4 x (Age 62) & $0.288^{* * *}$ & {$[0.090]$} \\
AC4 x (Age 63) & $0.195^{* * *}$ & {$[0.075]$} \\
AC4 x (Age 64) & $0.156^{*}$ & {$[0.085]$} \\
AC5 (eligibility age 64.5 to 65) x (Age 60) & $0.329^{* * *}$ & {$[0.091]$} \\
AC5 x (Age 61) & 0.073 & {$[0.080]$} \\
AC5 x (Age 62) & 0.200 & {$[0.123]$} \\
Age 60 & $0.376^{* *}$ & {$[0.149]$} \\
Age 61 & $0.496^{* * *}$ & {$[0.143]$} \\
Age 62 & $0.373^{* * *}$ & {$[0.136]$} \\
Age 63 & $0.372^{* * *}$ & {$[0.136]$} \\
Age 64 & $0.348^{* * *}$ & {$[0.132]$} \\
Bachelor & $0.201^{* * *}$ & {$[0.034]$} \\
Other Non-School Qualifications & $0.117^{* * *}$ & {$[0.034]$} \\
Household Size & -0.067 & {$[0.055]$} \\
\hline Adjusted R & & 0.36 \\
Observations & & 1633 \\
\hline
\end{tabular}

Total Estimated Cohort Impact ${ }^{4}$

$\begin{array}{lll}A C 1 & 0.384 * & {[0.230]} \\ A C 2 & 0.383^{* *} & {[0.195]} \\ A C 3 & 0.480^{* *} & {[0.224]} \\ A C 4 & 0.995^{* * *} & {[0.207]} \\ A C 5 & 0.602 * * * & {[0.171]}\end{array}$

Estimated Average Response to Homogenous Treatment ${ }^{5}$

Treatment (AC1-AC5)

$0.221^{* * *} \quad[0.076]$

1. Regressions include controls for state of residence.

2. Bootstraped standard errors, based on 999 replications, are in square brackets [].

3. ** significant at $1 \%, * *$ significant at $5 \%$; ${ }^{*}$ significant at $10 \%$

4. The cohort impact is the sum of the coefficients on age dummies of a given cohort.

5.This is the birth-cohort specific weighted average impact: $1 / 5 \sum_{t=1}^{5}\left(\sum_{i=60}^{64} \mathrm{FAge}_{\mathrm{i}} \mathrm{FCohort}_{\mathrm{t}} / \mathrm{t}\right)$ 


\begin{tabular}{|c|c|c|c|c|c|c|c|c|}
\hline & \multicolumn{4}{|c|}{ Males 60 to $69^{2}$} & \multicolumn{4}{|c|}{ Males 60 to $64^{3}$} \\
\hline & \multicolumn{6}{|c|}{ Age Difference $>0^{4}$} & \multirow{2}{*}{\multicolumn{2}{|c|}{$\begin{array}{c}\text { Age Difference }>04 \\
(4)\end{array}$}} \\
\hline & \multicolumn{2}{|c|}{$(1)$} & \multicolumn{2}{|c|}{$(2)$} & \multicolumn{2}{|c|}{ (3) } & & \\
\hline \multicolumn{9}{|c|}{ Wife's Age Pension Eligibility Age 60.5 to 61 (AC1) } \\
\hline AC1 x (Husband age 60) & 0.030 & {$[0.198]$} & & & 0.018 & {$[0.191]$} & & \\
\hline AC1 $\times$ (Husband age 61) & -0.026 & {$[0.111]$} & $0.505^{*}$ & {$[0.260]$} & -0.041 & {$[0.130]$} & $0.477^{* *}$ & [0.234] \\
\hline AC1 $\times$ (Husband age 62) & -0.043 & [0.112] & -0.095 & [0.169] & -0.037 & {$[0.120]$} & -0.085 & [0.173] \\
\hline AC1 $\times$ (Husband age 63) & 0.048 & [0.095] & -0.118 & [0.119] & 0.053 & [0.103] & -0.128 & [0.113] \\
\hline AC1 $\times$ (Husband age 64) & $0.131^{*}$ & {$[0.076]$} & 0.168 & {$[0.106]$} & 0.127 & {$[0.106]$} & 0.151 & [0.113] \\
\hline AC1 $\times$ (Husband age 65-69) & 0.033 & {$[0.032]$} & 0.033 & [0.037] & & & & \\
\hline \multicolumn{9}{|c|}{ Wife's Age Pension E ligibility Age 61.5 to 62 (AC2) } \\
\hline AC2 $\times$ (Husband age 60) & 0.003 & [0.159] & & & -0.001 & {$[0.172]$} & & \\
\hline AC2 $\times$ (Husband age 61) & 0.174 & {$[0.147]$} & $0.753 * * *$ & [0.281] & 0.173 & {$[0.145]$} & $0.755^{* * *}$ & [0.259] \\
\hline AC2 $\times$ (Husband age 62) & -0.087 & [0.114] & -0.138 & [0.167] & -0.078 & [0.096] & -0.123 & [0.166] \\
\hline AC2 $\times$ (Husband age 63) & $0.137^{*}$ & {$[0.082]$} & 0.03 & {$[0.110]$} & $0.144^{*}$ & [0.085] & 0.038 & [0.110] \\
\hline AC2 $\times$ (Husband age 64) & 0.062 & {$[0.088]$} & 0.07 & [0.090] & 0.060 & {$[0.072]$} & 0.067 & {$[0.090]$} \\
\hline AC2 $\times$ (Husband age 65-69) & $0.133 * * *$ & {$[0.032]$} & $0.133 * * *$ & {$[0.035]$} & & & & \\
\hline \multicolumn{9}{|c|}{ Wife's Age Pension E ligibility Age 61.5 to 62 (AC3) } \\
\hline AC3 $\times$ (Husband age 60) & 0.058 & {$[0.134]$} & & & 0.050 & {$[0.142]$} & & \\
\hline AC3 $\times$ (Husband age 61) & 0.110 & {$[0.146]$} & $0.473^{*}$ & {$[0.244]$} & 0.105 & {$[0.121]$} & $0.479^{* *}$ & {$[0.229]$} \\
\hline AC3 $\times$ (Husband age 62) & -0.148 & {$[0.117]$} & $-0.262^{*}$ & [0.153] & -0.143 & {$[0.108]$} & -0.24 & [0.154] \\
\hline AC3 $\times$ (Husband age 63) & $0.138^{*}$ & {$[0.080]$} & 0.034 & {$[0.105]$} & $0.139 *$ & {$[0.079]$} & 0.023 & [0.108] \\
\hline AC3 $\times$ (Husband age 64) & 0.113 & {$[0.086]$} & 0.103 & {$[0.092]$} & 0.111 & {$[0.086]$} & 0.095 & [0.095] \\
\hline AC3 $\times$ (Husband age 65-69) & $0.078^{* *}$ & {$[0.033]$} & $0.078^{* *}$ & {$[0.035]$} & & & & \\
\hline \multicolumn{9}{|c|}{ Wife's Age Pension E ligibility Age 62.5 to 63 (AC4) } \\
\hline AC4 $\times$ (Husband age 60) & 0.008 & [0.159] & & & 0.003 & [0.154] & & \\
\hline AC4 $\times$ (Husband age 61) & $0.221^{*}$ & [0.124] & $0.570^{* *}$ & {$[0.249]$} & $0.217^{*}$ & {$[0.131]$} & $0.581^{* *}$ & [0.229] \\
\hline AC4 $\times$ (Husband age 62) & -0.017 & {$[0.097]$} & -0.033 & {$[0.150]$} & -0.019 & {$[0.102]$} & -0.042 & [0.153] \\
\hline AC4 $\times$ (Husband age 63) & $0.239 * * *$ & {$[0.076]$} & 0.163 & [0.111] & $0.240 * * *$ & {$[0.072]$} & 0.145 & [0.107] \\
\hline AC4 $\times$ (Husband age 64) & 0.113 & {$[0.076]$} & 0.113 & [0.089] & 0.112 & {$[0.079]$} & 0.107 & [0.087] \\
\hline AC4 $\times$ (Husband age 65-69) & $0.138 * * *$ & {$[0.035]$} & $0.137^{* * *}$ & {$[0.032]$} & & & & \\
\hline \multicolumn{9}{|c|}{ Wife's Age Pension E ligibility Age 63.5 to 64 (AC5) } \\
\hline AC5 $\times$ (Husband age 60) & 0.019 & {$[0.138]$} & & & 0.006 & {$[0.126]$} & & \\
\hline AC5 $\times$ (Husband age 61) & $0.319 * * *$ & {$[0.118]$} & $0.720 * * *$ & {$[0.239]$} & $0.307^{* *}$ & [0.144] & $0.721 * * *$ & [0.219] \\
\hline AC5 $\times$ (Husband age 62) & -0.012 & {$[0.087]$} & -0.123 & {$[0.146]$} & -0.011 & {$[0.106]$} & -0.113 & {$[0.150]$} \\
\hline AC5 $\times$ (Husband age 63) & $0.171^{* *}$ & {$[0.076]$} & 0.069 & {$[0.100]$} & $0.169^{*}$ & {$[0.096]$} & 0.051 & [0.104] \\
\hline AC5 $\times$ (Husband age 64) & 0.094 & [0.079] & 0.112 & {$[0.091]$} & 0.092 & {$[0.097]$} & 0.101 & [0.096] \\
\hline AC5 $\times$ (Husband age 65-69) & $0.238 * * *$ & [0.049] & $0.237 * * *$ & {$[0.053]$} & & & & \\
\hline
\end{tabular}


Husband

\begin{tabular}{|c|c|c|c|c|c|c|c|c|}
\hline Age 60 & $0.699 * * *$ & [0.139] & & & $0.806 * * *$ & {$[0.178]$} & & \\
\hline Age 61 & $0.486 * * *$ & [0.125] & 0.085 & {$[0.248]$} & $0.599 * * *$ & [0.168] & 0.284 & {$[0.230]$} \\
\hline Age 62 & $0.658^{* * *}$ & [0.125] & $0.783^{* * *}$ & [0.176] & $0.760 * * *$ & [0.152] & $0.975^{* * *}$ & [0.192] \\
\hline Age 63 & $0.437 * * *$ & [0.111] & $0.563^{* * *}$ & [0.144] & $0.540 * * *$ & [0.149] & $0.786^{* * *}$ & [0.164] \\
\hline Age 64 & $0.405^{* * *}$ & [0.113] & $0.415^{* * *}$ & [0.139] & $0.510 * * *$ & [0.144] & $0.634 * * *$ & [0.162] \\
\hline Age 65-69 & $0.227^{* *}$ & [0.101] & $0.254^{* *}$ & [0.123] & & & & \\
\hline Bachelor & $0.108^{* * *}$ & {$[0.028]$} & $0.118 * * *$ & {$[0.027]$} & $0.119 * * *$ & {$[0.031]$} & $0.149 * * *$ & [0.045] \\
\hline Other Non-School Qualifn & 0.015 & [0.023] & 0.018 & {$[0.021]$} & 0.015 & [0.026] & 0.023 & [0.038] \\
\hline \multicolumn{9}{|l|}{ Wife } \\
\hline Age 61 & -0.002 & [0.027] & \multicolumn{2}{|c|}{$-0.007[0.030]$} & -0.007 & [0.037] & -0.02 & [0.041] \\
\hline Age 62 & 0.016 & [0.031] & \multicolumn{2}{|c|}{$0.01[0.033]$} & 0.003 & [0.045] & -0.024 & [0.051] \\
\hline Age 63 & 0.023 & [0.034] & \multicolumn{2}{|c|}{$0.023[0.033]$} & 0.021 & [0.040] & 0.02 & [0.073] \\
\hline Age 64 & -0.018 & [0.031] & \multicolumn{2}{|c|}{$-0.024[0.033]$} & -0.023 & {$[0.047]$} & & \\
\hline Bachelor & $0.074 * * *$ & {$[0.025]$} & $0.085^{* * *}$ & [0.028] & $0.073^{* *}$ & [0.035] & $0.101^{* *}$ & [0.049] \\
\hline Other Non-School Qualifn & $0.073 * *$ & [0.033] & $0.070 * *$ & [0.031] & 0.051 & [0.039] & 0.032 & [0.050] \\
\hline Household Size & -0.052 & {$[0.041]$} & -0.062 & [0.053] & $-0.091^{*}$ & {$[0.051]$} & $-0.141 * *$ & [0.058] \\
\hline Observations & \multicolumn{2}{|c|}{3,071} & \multicolumn{2}{|c|}{2,429} & \multicolumn{2}{|c|}{1,633} & \multicolumn{2}{|c|}{991} \\
\hline Adjusted $\mathrm{R}^{2}$ & \multicolumn{2}{|c|}{0.444} & \multicolumn{2}{|c|}{0.404} & \multicolumn{2}{|c|}{0.509} & \multicolumn{2}{|c|}{0.508} \\
\hline
\end{tabular}

Notes:1. Regression also includes controls for state of residence. 2-The sample contains married males aged 60 to 69 with spouses aged 60 to 64 . 3-The sample contains married males aged 60 to 64 with spouses aged 60 to 64 . 4- Agediff is the age difference between spouses defined as age of the husband minus age of the wife. In these specifications, husband is older than wife, as a result males aged 61 and above. 


\section{Appendix Table 3}

First Stage IV Estimates - Table 6

Dependent Variable : Wife's LFP

Males 60 to 69

IV

Wife's Age

Age 60

$0.137 * * *$

[0.026]

$0.047^{*}$

[0.025]

$0.066^{* * *}$

[0.024]

0.015

[0.023]

Husband's Age

Age 60

Age 61

$0.101^{* * *}$

[0.037]

0.045

Husband Education

Bachelor

Wife Education

Bachelor

Other Non-School Qualifications

Home Owner

Without Mortgage

Household Size

Instruments- Wife born between

1/July/1935 - 30/June/1938

1/July/1938 - 30/June/1941

1/July/1941 - 30/June/1944

1/July/1944 - 30/June/1947

1/July/1947 - 30/June/1952
[0.031]

0.043

[0.028]

$0.056 * *$

[0.024]

0.012

[0.024]

0.03

[0.024]

0.001

[0.018]

$0.198 * * *$

[0.025]

$0.125^{* * *}$

[0.025]

$0.233 * * *$

[0.034]

$-0.188^{* * *}$

[0.026]

$-0.072$

[0.044]

0.029

[0.033]

0.013

[0.025]

[0.037]

0.03

[0.032]

0.043

[0.029]

$0.186^{* * *}$

[0.036]

$0.116^{* * *}$

[0.034]

$0.313^{* * *}$

[0.045]

$-0.182^{* * *}$

[0.033]

$-0.059$

[0.052]

0.068

[0.044]

0.044

[0.036]

0.072 *

[0.040]

$0.165^{* * *}$

[0.037]

$0.155^{* * *}$ 
[0.032] [0.043]

Constant

0.133

0.036

[0.095]

[0.122]

$\mathrm{R}^{2}$

0.121

0.110 


\section{Appendix Table 4}

Effect of Wife's Participation on Husband's Labour Force Participation

\begin{tabular}{|c|c|c|c|c|}
\hline & \multicolumn{2}{|c|}{ Males 60 to 69} & \multicolumn{2}{|c|}{ Males 60 to 64} \\
\hline & OLS & IV & OLS & IV \\
\hline Wife's Labour Force Participation & $\begin{array}{c}0.436^{* * *} \\
{[0.019]}\end{array}$ & $\begin{array}{c}0.716^{* * *} \\
{[0.145]}\end{array}$ & $\begin{array}{c}0.430 * * * \\
{[0.024]}\end{array}$ & $\begin{array}{c}0.493^{* *} \\
{[0.211]}\end{array}$ \\
\hline \multicolumn{5}{|l|}{ Wife } \\
\hline Age 60 & $\begin{array}{l}-0.032 \\
{[0.024]}\end{array}$ & $\begin{array}{c}-0.079 * * \\
{[0.036]}\end{array}$ & $\begin{array}{c}-0.036 \\
{[0.041]}\end{array}$ & $\begin{array}{c}-0.046 \\
{[0.054]}\end{array}$ \\
\hline Age 61 & $\begin{array}{c}0.009 \\
{[0.023]}\end{array}$ & $\begin{array}{c}-0.011 \\
{[0.027]}\end{array}$ & $\begin{array}{c}0.001 \\
{[0.043]}\end{array}$ & $\begin{array}{c}-0.003 \\
{[0.045]}\end{array}$ \\
\hline Age 62 & $\begin{array}{c}0.011 \\
{[0.024]}\end{array}$ & $\begin{array}{l}-0.011 \\
{[0.026]}\end{array}$ & $\begin{array}{c}0 \\
{[0.043]}\end{array}$ & $\begin{array}{l}-0.004 \\
{[0.045]}\end{array}$ \\
\hline Age 63 & $\begin{array}{c}0.035 \\
{[0.023]}\end{array}$ & $\begin{array}{c}0.028 \\
{[0.024]}\end{array}$ & $\begin{array}{c}0.034 \\
{[0.047]}\end{array}$ & $\begin{array}{c}0.031 \\
{[0.047]}\end{array}$ \\
\hline \multicolumn{5}{|l|}{ Husband } \\
\hline Age 60 & $\begin{array}{c}0.314^{* * *} \\
{[0.037]}\end{array}$ & $\begin{array}{c}0.283^{* * *} \\
{[0.041]}\end{array}$ & $\begin{array}{c}0.173 * * * \\
{[0.039]}\end{array}$ & $\begin{array}{c}0.167^{* * *} \\
{[0.046]}\end{array}$ \\
\hline Age 61 & $\begin{array}{c}0.280 * * * \\
{[0.033]}\end{array}$ & $\begin{array}{c}0.265^{* * *} \\
{[0.035]}\end{array}$ & $\begin{array}{c}0.139 * * * \\
{[0.037]}\end{array}$ & $\begin{array}{c}0.137 * * * \\
{[0.038]}\end{array}$ \\
\hline Age 62 & $\begin{array}{c}0.245^{* * *} \\
{[0.026]}\end{array}$ & $\begin{array}{c}0.231 * * * \\
{[0.028]}\end{array}$ & $\begin{array}{c}0.104^{* * *} \\
{[0.031]}\end{array}$ & $\begin{array}{c}0.102^{* * *} \\
{[0.033]}\end{array}$ \\
\hline Age 63 & $\begin{array}{c}0.202 * * * \\
{[0.024]}\end{array}$ & $\begin{array}{c}0.186 * * * \\
{[0.027]}\end{array}$ & $\begin{array}{c}0.060 * * \\
{[0.029]}\end{array}$ & $\begin{array}{l}0.057^{*} \\
{[0.032]}\end{array}$ \\
\hline Age 64 & $\begin{array}{c}0.142 * * * \\
{[0.024]}\end{array}$ & $\begin{array}{c}0.138 * * * \\
{[0.025]}\end{array}$ & & \\
\hline \multicolumn{5}{|l|}{ Husband Education } \\
\hline Bachelor & $\begin{array}{c}0.089 * * * \\
{[0.023]}\end{array}$ & $\begin{array}{c}0.080 * * * \\
{[0.026]}\end{array}$ & $\begin{array}{c}0.097 * * * \\
{[0.032]}\end{array}$ & $\begin{array}{c}0.095^{* * *} \\
{[0.034]}\end{array}$ \\
\hline Other Non-School Qualifications & $\begin{array}{c}0.014 \\
{[0.018]}\end{array}$ & $\begin{array}{c}0.015 \\
{[0.018]}\end{array}$ & $\begin{array}{c}0.005 \\
{[0.025]}\end{array}$ & $\begin{array}{c}0.004 \\
{[0.028]}\end{array}$ \\
\hline \multicolumn{5}{|l|}{ Wife Education } \\
\hline Bachelor & $\begin{array}{l}-0.017 \\
{[0.023]}\end{array}$ & $\begin{array}{c}-0.077^{* *} \\
{[0.039]}\end{array}$ & $\begin{array}{c}-0.013 \\
{[0.034]}\end{array}$ & $\begin{array}{l}-0.026 \\
{[0.056]}\end{array}$ \\
\hline Other Non-School Qualifications & $\begin{array}{c}0.017 \\
{[0.024]}\end{array}$ & $\begin{array}{l}-0.016 \\
{[0.029]}\end{array}$ & $\begin{array}{c}-0.008 \\
{[0.034]}\end{array}$ & $\begin{array}{c}-0.014 \\
{[0.040]}\end{array}$ \\
\hline Home Owner & $\begin{array}{c}0.091 * * \\
{[0.037]}\end{array}$ & $\begin{array}{c}0.02 \\
{[0.052]}\end{array}$ & $\begin{array}{c}0.066 \\
{[0.051]}\end{array}$ & $\begin{array}{c}0.045 \\
{[0.086]}\end{array}$ \\
\hline Without Mortgage & $\begin{array}{c}-0.147^{* * *} \\
{[0.025]}\end{array}$ & $\begin{array}{c}-0.088^{* *} \\
{[0.040]}\end{array}$ & $\begin{array}{c}-0.143 * * * \\
{[0.030]}\end{array}$ & $\begin{array}{c}-0.131^{* *} \\
{[0.053]}\end{array}$ \\
\hline Household Size & $\begin{array}{l}-0.029 \\
{[0.042]}\end{array}$ & $\begin{array}{c}-0.008 \\
{[0.046]}\end{array}$ & $\begin{array}{l}-0.058 \\
{[0.050]}\end{array}$ & $\begin{array}{c}-0.054 \\
{[0.052]}\end{array}$ \\
\hline Constant & $\begin{array}{c}0.197 * * \\
{[0.091]}\end{array}$ & $\begin{array}{c}0 \\
{[0.098]}\end{array}$ & $\begin{array}{c}0.430 * * * \\
{[0.121]}\end{array}$ & $\begin{array}{c}0.423 * * * \\
{[0.125]}\end{array}$ \\
\hline $\mathrm{R}^{2}$ & 0.280 & 0.221 & 0.212 & 0.209 \\
\hline Observations & 3,071 & 3,071 & 1,633 & 1,633 \\
\hline
\end{tabular}




\begin{tabular}{|c|c|c|c|c|}
\hline & \multicolumn{2}{|c|}{ Male DSP Receipt } & \multicolumn{2}{|c|}{ Household DSP Receipt $^{3}$} \\
\hline & \multicolumn{2}{|c|}{$(1)$} & \multicolumn{2}{|c|}{$(2)$} \\
\hline \multicolumn{5}{|c|}{ Wife's Age Pension Eligibility Age 60.5 to 61 (AC1) } \\
\hline AC1 $\times$ (Husband age 60) & 0.025 & [0.182] & 0.019 & [0.173] \\
\hline AC1 $\times$ (Husband age 61) & 0.026 & [0.128] & 0.053 & [0.136] \\
\hline AC1 $\times$ (Husband age 62) & 0.005 & [0.104] & -0.002 & [0.092] \\
\hline AC1 $\times$ (Husband age 63) & -0.074 & [0.092] & -0.098 & [0.089] \\
\hline AC1 $\times$ (Husband age 64) & -0.028 & [0.099] & 0.005 & [0.095] \\
\hline \multicolumn{5}{|l|}{ AC1 x (Husband age 65-69) } \\
\hline \multicolumn{5}{|c|}{ Wife's Age Pension E ligibility Age 61.5 to 62 (AC2) } \\
\hline AC2 $\times$ (Husband age 60) & -0.043 & [0.148] & -0.055 & [0.137] \\
\hline AC2 $\times$ (Husband age 61) & -0.149 & [0.136] & -0.15 & [0.126] \\
\hline AC2 $\times$ (Husband age 62) & -0.016 & [0.077] & 0.001 & [0.080] \\
\hline AC2 $\times$ (Husband age 63) & -0.059 & [0.094] & -0.065 & [0.084] \\
\hline AC2 $\times$ (Husband age 64) & -0.028 & [0.081] & 0.004 & [0.075] \\
\hline \multicolumn{5}{|l|}{ AC2 $\times$ (Husband age 65-69) } \\
\hline \multicolumn{5}{|c|}{ Wife's Age Pension E ligibility Age 61.5 to 62 (AC3) } \\
\hline AC3 $\times$ (Husband age 60) & 0.026 & [0.137] & 0.048 & [0.140] \\
\hline AC3 $\times$ (Husband age 61) & -0.094 & [0.119] & -0.098 & [0.122] \\
\hline AC3 $\times$ (Husband age 62) & 0.055 & [0.099] & 0.068 & [0.088] \\
\hline AC3 $\times$ (Husband age 63) & -0.046 & [0.072] & -0.04 & [0.082] \\
\hline AC3 $\times$ (Husband age 64) & 0.008 & [0.071] & 0.034 & [0.080] \\
\hline \multicolumn{5}{|l|}{ AC3 $\times$ (Husband age 65-69) } \\
\hline \multicolumn{5}{|c|}{ Wife's Age Pension E ligibility Age 62.5 to 63 (AC4) } \\
\hline AC4 $\times$ (Husband age 60) & 0.125 & [0.147] & 0.123 & [0.144] \\
\hline AC4 $\times$ (Husband age 61) & -0.173 & [0.121] & -0.153 & [0.116] \\
\hline AC4 $\times$ (Husband age 62) & 0.042 & [0.080] & 0.089 & [0.084] \\
\hline AC4 $\times$ (Husband age 63) & $-0.163^{*}$ & [0.084] & $-0.143^{*}$ & [0.074] \\
\hline AC4 $\times$ (Husband age 64) & -0.081 & [0.073] & 0 & [0.073] \\
\hline \multicolumn{5}{|l|}{ AC4 x (Husband age 65-69) } \\
\hline \multicolumn{5}{|c|}{ Wife's Age Pension E ligibility Age 63.5 to 64 (AC5) } \\
\hline AC5 $\times$ (Husband age 60) & 0.110 & [0.141] & 0.132 & [0.140] \\
\hline AC5 $\times$ (Husband age 61) & -0.153 & [0.115] & -0.148 & [0.120] \\
\hline AC5 $\times$ (Husband age 62) & 0.108 & [0.087] & 0.13 & [0.085] \\
\hline AC5 $\times$ (Husband age 63) & -0.042 & [0.084] & -0.067 & [0.081] \\
\hline AC5 $\times$ (Husband age 64) & 0.056 & [0.081] & 0.139 & [0.085] \\
\hline
\end{tabular}


Husband

\begin{tabular}{|c|c|c|c|c|}
\hline Age 60 & 0.024 & [0.206] & 0.07 & {$[0.180]$} \\
\hline Age 61 & 0.144 & [0.176] & 0.192 & [0.160] \\
\hline Age 62 & -0.012 & [0.157] & 0.035 & {$[0.136]$} \\
\hline Age 63 & 0.142 & [0.143] & 0.206 & [0.137] \\
\hline Age 64 & 0.117 & [0.142] & 0.165 & {$[0.130]$} \\
\hline \multicolumn{5}{|l|}{ Age 65-69 } \\
\hline Bachelor & $-0.181 * * *$ & [0.025] & $-0.199 * * *$ & [0.027] \\
\hline Other Non-School Qualifications & $-0.059 * *$ & [0.026] & $-0.051^{*}$ & {$[0.026]$} \\
\hline \multicolumn{5}{|l|}{ Wife } \\
\hline Age 61 & 0.031 & [0.028] & 0.028 & [0.028] \\
\hline Age 62 & 0.042 & [0.033] & 0.034 & {$[0.032]$} \\
\hline Age 63 & 0.023 & [0.043] & 0.011 & [0.035] \\
\hline Age 64 & 0.061 & [0.047] & 0.037 & [0.043] \\
\hline Bachelor & $-0.083 * * *$ & [0.024] & $-0.096 * * *$ & [0.028] \\
\hline Other Non-School Qualifications & -0.040 & [0.033] & $-0.060 *$ & [0.031] \\
\hline Household Size & 0.074 & [0.062] & 0.057 & {$[0.056]$} \\
\hline Adjusted $\mathrm{R}^{2}$ & \multicolumn{2}{|c|}{0.294} & \multicolumn{2}{|c|}{0.321} \\
\hline Observations & \multicolumn{2}{|c|}{1633} & \multicolumn{2}{|c|}{1633} \\
\hline
\end{tabular}

Notes: 1-Regressions also includes controls for state of residence. 2-The sample contains married males aged 60 to 64 with spouses aged 60 to 64 . 3-The dependent variable is whether anyone in the household is receiving disability insurance benefits. 4- Bootstraped standard errors, based on 999 replications, are in square brackets []. 5- *** significant at $1 \%,{ }^{* *}$ significant at $5 \%$; ${ }^{*}$ significant at $10 \%$ 